\title{
EXPOSURE TO ULTRAVIOLET RADIATION CAUSES PROTEOMIC CHANGES IN EMBRYOS OF THE PURPLE SEA URCHIN, STRONGYLOCENTROTUS PURPURATUS
}

\author{
A Thesis \\ presented to \\ the Faculty of California Polytechnic State University, \\ San Luis Obispo
}

\begin{abstract}
In Partial Fulfillment
of the Requirements for the Degree

Master of Science in Biological Sciences
\end{abstract}

by

Joseph Paul Campanale

July 2009 
(C) 2008

Joseph Paul Campanale

ALL RIGHTS RESERVED

COMMITTEE MEMBERSHIP 
TITLE: $\quad$ EXPOSURE TO ULTRAVIOLET RADIATION CAUSES PROTEOMIC CHANGES IN EMBRYOS OF THE PURPLE SEA URCHIN, STRONGYLOCENTROTUS PURPURATUS

AUTHOR: $\quad$ Joseph Paul Campanale

DATE SUBMITTED: July 2009

COMMITTE CHAIR: $\quad$ Dr. Nikki Adams, Associate Professor, Biological Sciences Department, California Polytechnic State University, San Luis Obispo

COMMITTEE MEMBER: Dr. Lars Tomanek, Assistant Professor, Biological Sciences Department, California Polytechnic State University, San Luis Obispo

COMMITTEE MEMBER: Dr. Kathleen Foltz, Associate Professor, Department of Molecular, Cellular and Developmental Biology, University of California, Santa Barbara

ABSTRACT 


\title{
EXPOSURE TO ULTRAVIOLET RADIATION CAUSES PROTEOMIC CHANGES IN EMBRYOS OF THE PURPLE SEA URCHIN, STRONGYLOCENTROTUS PURPURATUS
}

\author{
Joseph Paul Campanale
}

The amount of solar ultraviolet radiation (UVR, 290-400 nm) reaching Earth's surface is increasing due to ozone depletion and global climate change. Embryos of the purple sea urchin, Strongylocentrotus purpuratus, provide an ideal system for examining how UVR affects developing marine organisms and cells in general. To model the protein-mediated cell cycle response to UV-irradiation, six batches of $S$. purpuratus embryos were exposed to UVR, monitored for delays in the first mitotic division and examined for global proteomic changes. Embryos from each batch were exposed to or protected from artificial UVR for 25 or $60 \mathrm{~min}$. Embryos treated with UVR for 60 min cleaved an average of 23.24 min ( \pm 1.92 s.e.m) later than the UVprotected embryos. Protein expression of UV-protected and UV-treated embryos was examined at 30 and 90 min post-fertilization using two dimensional sodium dodecyl sulfate polyacrylamide gel electrophoresis (2D SDS-PAGE) and mass spectrometry (MS). Proteins were isoelectrically focused ( $\mathrm{pH} 4-7)$ and separated by molecular weight using SDS-PAGE. At least 1,306 protein spots were detected in all gels. A total of 171 protein spots ( $13 \%$ of the detected proteome) migrated differently in UVtreated embryos at $30 \mathrm{~min}$ post-fertilization and 187 spots $(14 \%)$ at 90 min postfertilization (2-way ANOVA, $\mathrm{P}=0.03, \mathrm{n}=6$ ). Our results identify the differential migration of proteins from multiple cellular pathways and are the first to indicate that the mechanisms involved in the protein mediated UV-induced developmental delay are integrated among pathways for cellular stress, protein turnover and translation, signal transduction, general metabolism and involve the cytoskeleton.

Keywords: ultraviolet radiation, sea urchin embryo, proteome response 


\section{ACKNOWLEDGMENTS}

There are many people who have helped me develop as a student, a biologist and more importantly a scientist. I have grown into the person, the biologist and scientist I am today with the help and guidance of the entire Biological Science Department at California Polytechnic State University, San Luis Obispo.

A special thanks goes to all of the departmental staff members who were always available in time of need. From construction projects to equipment maintenance, they were devoted to assisting in any way possible. I would also like to thank all of the faculty, past and present, who have been my mentors in and out of the classroom. They have each helped inspire me to reach my full potential.

A special thank you goes to Shane Anderson and Christoph Pierre at The University of California at Santa Barbara who collected all of the gravid sea urchins used to complete this work.

I would also like to thank all of the lab members from the labs of Nikki Adams, Lars Tomanek and Kathy Foltz including: Michelle Roux, Sarah Gravem, Sarah Strickler, Lindsey Chang, Melissa Daugherty, Anniken Liden, Molly Baker, Shannon Farris, Tia DiTomaso, John Burns, Elise Suronen, Megan Mallonee, Eric Maher, Carolyn Ewers, Allison Malicoat, Lauren Hitt and Jacob Valenzuela. I owe this long list of people many thanks for all of their support, inspiration, collaboration, and for teaching me to be a part of a lab family and the scientific community. It really has been a pleasure to work with and learn from such a talented set of people!

Thank you to CSUPERB, who funded this work through a Faculty Seed Grant awarded to Nikki L. Adams. Funding was also provided through NSF Grant IBN 0417003 awarded to N. Adams.

I would like to thank Greg Russo for all of his patience, understanding and support during the completion of my Masters Degree. He is a loving husband with an

endearing heart. Without Greg, I would not have had the strength to complete all that I have! I love you.

Finally I would like to extend a sincere thank you to all of my committee members. Nikki Adams, Lars Tomanek and Kathy Foltz have been a source of inspiration for the last three years and will continue to be my mentors as I move forward in the attainment of my $\mathrm{PhD}$. The respect and admiration that $\mathrm{I}$ have for all three of these people cannot be explained in words. I extend extra special gratitude to Nikki Adams for her unwavering support in me, her belief in me and my work and for her dedication. Nikki serves as an instrumental figure to me, one I only hope to mirror one day. Thank you Lars Tomanek for setting the bar. Thank you Kathy Foltz for never letting me lose sight of the bar. Thank you Nikki Adams for all of your guidance, invaluable mentorship and trust in me, it is because of you that I was able to reach the bar.

\section{TABLE OF CONTENTS}




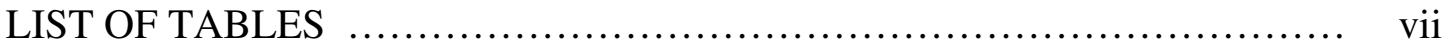

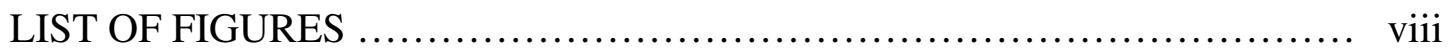
CHAPTER

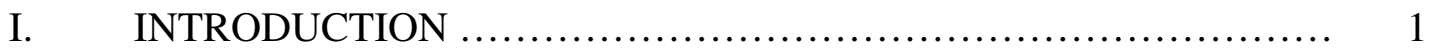

II. MANUSCRIPT ........................................ 14

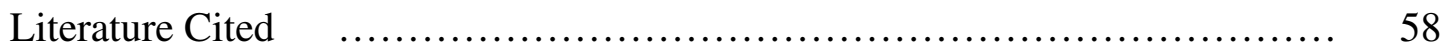

LIST OF TABLES

Table Page 
1. Identification of proteins differentially regulated after UVR exposure using MS + MS/MS from the $S$. purpuratus proteome

$35-36$ 


\section{LIST OF FIGURES}

Figure

1. Fig. 1. Graph of average cleavage rates of six batches of UV-protected and UV-treated $S$. purpuratus embryos .....................................

2. Fig. 2. Overlay of fusion averaged $2 \mathrm{D}$ gel images (proteome maps) for six batches of $S$. purpuratus embryos exposed to or protected from UVR.......

3. Fig. 3. Expression density map for MALDI-TOF MS + MS/MS identified proteins showing a significant differentially regulated spot volume... 


\section{Chapter 1}

\section{Introduction}

Statement of problem: Since the early 1900's, scientists have recognized that ultraviolet radiation has negative effects on organisms and that sea urchin embryos can be used as a model system to examine cellular responses to UVR (Giese, 1938). Although many reports have detailed anomalies caused by UVR, such as delays in division, morphological abnormalities and death (Giese, 1964; Rustad, 1971), only recently have we had the power to examine these effects at the molecular level. We report the use of a proteomics (explained below) for providing a comprehensive, objective assessment of the UV-stressed sea urchin embryo proteome as a compliment to the reductionist, single molecule or pathway approaches. We provide clues about what causes developmental delays and abnormal development by identifying multiple proteins from many cellular pathways that appear to show a dynamic change in response to UVR. Conclusions from our inclusive assessment of UV-induced proteomic changes can provide more thorough information on how UVR affects overall cell regulation and may lead to the identification of biomarkers for UVR induced stress, cell death and disease.

UVR and ecosystem effects: Widespread release of ozone-depleting gasses over previous decades has led to reductions in Earth's ozone, increasing the total amount of ultraviolet radiation (UVR, 280-400 nm), particularly ultraviolet B (UVB, 280-320 nm) reaching Earth's surface (Madronich et al., 1998; McKenzie et al., 2007; Smith et al., 1992; WMO, 2007). The majority of ozone depletion is in polar regions; nevertheless, moderate increases of UVB in temperate regions $(\sim 7 \%$ in the 
summer and $35 \%$ in the winter) suggest temperate ecosystems may also be impacted (Kerr and McElroy, 1993). Despite global reductions in the release of ozonedepleting gasses, ozone levels are not expected to return to 1980 levels in polar regions until approximately the year 2050 (Madronich et al., 1998; McKenzie et al., $2003 ; 2007)$ and it is unclear whether levels of ozone will return to that seen before ozone thinning started in the 1970's (McKenzie et al., 2007).

Recent reports also emphasize that despite stabilization of ozone levels at temperate latitudes, UVB levels on Earth will continue to increase by a few percent per decade due to global climate change (McKenzie et al., 2003; 2007; WMO, 2007). The complex interactions among ozone depletion, climate change and UVR are mediated by multiple factors including atmospheric circulation patterns and atmospheric chemistry, and predictions for complete ozone stabilization are difficult to assess because changes in ozone can affect the climate (cloud formation and albedo) while changes in climate can in turn affect changes in ozone (Häder et al., 2007; McKenzie et al., 2007; United Nations Environment Programme, Environmental Effects Assessment Panel, 2004 and 2005).

Although the effects of ozone depletion and increased UVR have produced a rich body of literature detailing the potential impacts at the cellular and ecological levels (reviewed in Cullen and Neale, 1994; Day and Neale 2002; Häder, et al., $1998 ; 2005 ; 2007)$, there is a need to examine the synergistic effects of UVR with multiple stressors to evaluate the cumulative effects in marine species. For example, changes in ocean temperature and $\mathrm{pH}$ can result in water stratification that has a profound effect on the amount of chromophoric dissolved organic matter (CDOM) 
that is photobleached by UVR (Anderson et al., 2001; Häder et al., 2007). The photobleaching of CDOM results in enhanced penetration of UVR into the ocean and causes elevated UVR stress in shallow dwelling and planktonic organisms (Zepp et al., 2003). Furthermore, global climate change will produce elevated temperatures (Helmuth et al., 2002) and highly variable precipitation (Karl and Trenberth, 2003), which are already known to represent significant stressors to intertidal communities. Lesser et al. (1990) and Hoffman et al. (2003) have shown a dramatic interaction between UVR and temperature stress that can alter organismal responses to other abiotic environment. Studies by Przeslawski (2004), Przeslawski et al. (2005) and Russell and Phillips (2009) have highlighted the dramatic underestimation the effect of multiple stressors has on development of marine invertebrate embryos including osmotic, temperature and UVR stress.

Previous studies concluded that harmful levels of solar ultraviolet A (UVA, 321-400 nm) and UVB penetrate as much as several meters in organically rich coastal seawater in temperate regions (Adams et al., 2001; Karentz and Lutze, 1990; Tedetti and Sempere, 2006). Even at pre-ozone depletion levels, UVR stress is deleterious to molecular, biochemical and physiological functioning (Xiong et al., 1999) and has led to reductions in total productivity of phytoplankton and zooplankton, the foundation of marine food chains (Cullen and Neale, 1994; Williamson et al., 1994).

UVR is a driving force in both terrestrial and aquatic ecosystems, causing reductions in ecosystem function, alterations of trophic interactions and further, can result in mutation and altered cellular function in exposed organisms lacking UVR 
defenses (Caldwell et al., 1998; Häder et al., 2007). Cellular targets such as proteins, DNA and lipids absorb light differently and may vary in UV-sensitivity. Exposure to UVB radiation results in direct protein damage by photochemical degradation of tryptophan and tyrosine residues and destroys disulfide bonds required for proteinprotein interactions (Hollósy, 2002; Tevini 1993). UVB damages DNA through the production of cyclobutane pyrimidine dimers (CPD's) among other photoproducts (Imlay and Linn, 1988; Lesser et al., 2003; Peak and Peak, 1990; Setlow 1974; Tevini 1993). UVA makes up greater than $90 \%$ of the total UVR that reaches Earth's surface and causes photooxidative damage through the production of reactive oxygen species (ROS) that rapidly oxidize nucleic acids, proteins and lipids (Pourzand and Tyrrell, 1999; Tyrrell 1991).

Sea urchins as a model organism: Sea urchin embryos are an ideal system for studying the effects of UV-radiation on embryonic development and cells in general because they are easy to spawn, fertilize and culture in the laboratory. In addition, adults provide large amounts of gametes and embryos that divide synchronously, allowing for molecular and integrative physiological studies. More importantly, sea urchin embryos can be naturally fertilized and cultured in the lab under similar conditions found in the field since $S$. purpuratus are broadcast spawners.

Recently, the $S$. purpuratus genome was sequenced, and the repertoire of genes expressed in the eggs and embryo (the transcriptome) was analyzed, providing powerful tools for evaluating effects of UVR on this model species (Samanta et al., 2006 and Sodergren et al., 2006). S. purpuratus has been an instrumental model organism for studies that detail the genes used in 
biomineralization (Livingston et al., 2006) and intermediary metabolism (Goel and Mushegian, 2006), which are actively regulated during development and differentiation (Howard-Ashby et al., 2006). Sequencing of the genome also allowed a more extensive identification of the regulatory protein kinases, or the Kinome (Bradham et al., 2006) and the sea urchin complement of proteins used for cell cycle control (Fernandez-Guerra et al., 2006). Moreover, the genomic sequence has provided information about the number of proteins that are in the sea urchin genomic arsenal for chemical defense, including oxidative stress proteins involved in mediating UVR stress found in other organisms (Goldstone et al., 2006). These initial surveys of the genome provide a great deal of insight for the potential genetic regulation of basic sea urchin development in non-stressed conditions, but lack functional analysis, especially during stress.

Embryos are the most sensitive life stage of aquatic organisms and echinoid embryos (including sea urchins) have been used extensively as a valuable model embryonic system for studying eco-toxicological effects of environmental factors such as temperature, oxidative stress, chemical pollutants and UVR (Adams and Shick, 1996; Bancroft et al., 2007; Lesser et al., 2003; Pesando et al., 2003; Russo et al., 2003). Sea urchins inhabit all of Earth's major oceans and have developmental stages sensitive to UVR (Adams and Shick, 1996; 2001; Anderson et al., 1993; Lesser et al., 2003). Many live intertidally and broadcast spawn gametes that initially sink. Later embryonic stages start to swim and feed in the upper marine plankton (Bosch et al., 1987; Pennington and Emlet, 1986) where they are potentially exposed to elevated levels of UVR. 
The UV-sensitivity of gametes and embryos of sea urchins is well documented in studies that compare UV-protected to UV-irradiated sea urchin sperm, eggs and embryos. Reductions in the times for cell division and abnormal development and morphogenesis have been observed (Adams and Shick, 1996; 2001; Bonaventura et al., 2005; 2006). Specifically, sea urchins exposed to UVR as eggs or early embryos experience delayed completion of the first mitotic division, stalling in prophase of the cell cycle (Adams and Shick, 1996 and 2001; Giese, 1964; Rustad, 1971). The UV-induced developmental delay in sea urchin embryos has accelerated research on the particular effects of UVR in marine invertebrate embryos and the particular mechanisms cells use to defend themselves against UVstress.

Planktonic sea urchin embryos are microscopic and lack protective coverings, but have developed protective strategies to reduce the damaging effects of UVR. Embryos use rapid cell division and efficient DNA repair mechanisms to mediate UV-induced cellular damage (Häder et al., 2007). These embryos can also avoid light if held in static water (Miller and Emlet, 1997), but may not be able to control their position in a mixed water column (Denny and Shibata, 1989), possibly leaving them more vulnerable to sustained UVR exposure. Sea urchin embryos have indirect protective strategies, independent of the developmental program, to guard against UVR damage. Some embryos are supplied with natural sunscreens from the maternal diet, mycosporine-like amino acids (MAAs), that protect against some but not all damage caused by UVR (Adams and Shick, 1996 \& 2001; Dunlap and Shick, 1998). MAAs are provided maternally to eggs through the adult sea urchin's diet (Adams and Shick, 1996; Carroll and Shick, 1996) and resulting embryos with high 
concentrations of MAAs are more resistant to UVR damage than embryos with low levels of MAAs (Adams and Shick, 1996; 2001). Specifically, MAAs reduce the extent of UV-induced cleavage delay experienced by embryos (Adams and Shick, 1996).

Sea urchin embryos also sustain UV-induced DNA damage (Lesser et al, 2003; 2006). Common repair mechanisms utilized by cells in aquatic organisms are base excision repair (BER), nucleotide excision repair (NER), and mismatch repair for single-stranded breaks and homologous or non-homologous recombination for double stranded breaks (Sinha and Häder, 2002). Sea urchin embryos can also use photoreactivation to enzymatically reverse DNA damage, including the repair of CPDs. Early studies indicated that irradiating embryos with visible light augments most but not all of the UV-induced DNA damage and developmental delay (Akimoto and Shiroya, 1987; Marshak, 1949). Photoreactivation involves the use of UVA and photosynthetically active radiation (PAR, 401-700 nm) energy to activate photolyase, which splits DNA dimers created by UVR (Häder et al, 2007; Thoma, 1999). Importantly, studies have specifically documented the production of CPD's and photorepair in UVR stressed embryos (Akimoto and Shiroya, 1987; Lesser et al., 2003; 2006).

UV-induced DNA damage is a hallmark of UV-irradiation in sea urchin embryos, but interestingly, the action spectra for sea urchin division delays caused by UV-irradiation of eggs and embryos are more similar to protein absorption rather than just DNA absorption (Giese, 1964). UVR stress therefore is not only the result of DNA damage but also appears to manifest in part by damage to or regulation of the 
protein components in sea urchin embryos. Amino acids absorb UVR causing photodamage of proteins, which can lead to enzyme inactivation and protein destruction (Hollósy, 2002). UVB can also initiate cellular signals in mammalian immune cells by causing rapid tyrosine phosphorylations through tyrosine kinases, leading to activation of calcium signaling controlling a variety of cellular activities (Schieven et al, 1993). The fact that both UVB and UVA are important factors for the contribution to DNA and protein damage resulting in low survival of sea urchin embryos (Adams et al., 2009, in preparation; Lesser et al., 2006) has focused attention on how UVR affects the regulation of the cell cycle.

Cell cycle and UVR-stress: The cell cycle in somatic cells consists of four phases; gap 1 (G1), synthesis (S), gap $2(\mathrm{G} 2)$ and mitosis (M) phase. During S phase the cell replicates its DNA. During M phase chromosomes are separated and distributed among daughter cells as a result of the cell undergoing mitosis. S and $\mathrm{M}$ phase are separated by the Gap phases (G1 and G2) where cells grow in size and prepare for replication and mitosis (Norbury and Nurse, 1992). In embryonic cells, there are no gap phases and cells rapidly cycle between $\mathrm{S}$ and $\mathrm{M}$ phase as the large egg is subdivided into smaller and smaller cells. Early sea urchin embryos, like those of many other animals, do not transcribe their own genome and instead are dependent on maternally derived mRNAs stored in the eggs (Wei et al., 2006), so early cell cycles rely on maternal mRNAs and proteins. The short time periods between cell division observed in S. purpuratus embryos quickly produces motile larvae, which are able to swim and feed 48-72 hours post-fertilization. This strategy reduces the amount of time that the embryo is most vulnerable to predation, currents, toxins, and UVR (Strathmann et al., 2002). By rapidly dividing without slowing to protect or 
completely repair their DNA, sea urchin embryos may be able to promptly grow to the point where they can feed and then halt development to take care of any defective cells by repair and/or apoptosis (Epel, 2003).

In order to preserve the integrity of the genome, cells use checkpoints to regulate their entry and exit into phases of the cell cycle. Under normal conditions entry into mitosis is regulated by the Mitosis Promoting Factor (MPF). The MPF is composed of a cyclin-dependent kinase (Cdc2) and Cyclin B in sea urchins (Murray and Kirschner, 1989). Upon fertilization, Cyclin B is translated and binds to Cdc2 (which was present in the egg) forming the MPF (Hunt et al., 1992). MPF activity is regulated by specific protein kinases, which activate and inactivate $\mathrm{Cdc} 2$.

Species may have different mechanisms for regulating the cell cycle in response to DNA damage, but the proteins detecting and altering the cell cycle in response to DNA damage are highly conserved (Rhind and Russell, 2000). In general, eukaryotes use a homolog of ataxia talangiectasia mutated (ATM) to recognize DNA damage and or stalled replication forks. ATM then induces a cascade response that includes the protein kinase, Chk1, which continues a molecular cascade that is eventually responsible for causing the inactivation of $\mathrm{Cdc} 2$ and stopping entry into mitosis. Chk1 was first discovered in Schizosaccharomyces pombe and has since been identified in Saccharomyces cervisiae, Drosophila melanogaster (as Grapes), Xenopus laevis (as xChk1), and hChk1 in humans and mice (Rhind and Russell, 2000). Recent work on the sea urchin genome has identified a homolog in S. purpuratus, spChk1 (Sodergren et al., 2006; Goschke, 2005). Also, Adams et al. (2009, in preparation) observed that UVR causes delayed activation of the 
molecular controls on the sea urchin embryo cell cycle, specifically delayed dephosphorylation of $\mathrm{Cdc} 2$ of MPF.

Sea urchin responses to stress: Proteins and amino acids absorb UVR, resulting in photodamage (Hollósy, 2002). Heat-shock proteins (HSPs) may provide some protection from direct UV-damage to proteins and deactivated enzymes (Trautinger et al., 1996). Sea urchin embryos exposed to UVR during early cleavage stages elevate HSP70 in as little as 1 hour after exposure, in a dose dependent fashion and maintain elevated expression of HSP70 as much as 48 hours after exposure (Bonaventura et al., 2005; 2006). HSP70 helps cellular proteins fold properly and remain folded under both stressful and normal conditions. Mouse and human epidermal cells elevate the expression of HSP family proteins in response to UV-irradiation. Elevation of HSPs provide added protection against UVR-induced apoptosis, and further overexpression of the protein HSP70 can protect cells from accumulating UV-induced DNA damage in human cells (Trautinger et al., 1996).

Responses to stress involve coordinated cellular signaling including the control of the cell cycle, metabolism, transcription regulation, development and differentiation, apoptosis, and other cellular functions. Kinases which phosphorylate, and phosphatases which dephosphorylate proteins, regulate protein activity during cell division and during periods of stress. Recent investigation of the full complement of regulatory protein kinases (the Kinome) encoded in the S. purpuratus genome has shown that it contains 182 of the 186 subfamilies in the human kinome, and a few kinases that had not been seen in other organisms (Bradham et al., 2006). Importantly, the sea urchin kinome has fewer duplication events than the human 
genome, providing a relatively simple model to study specific kinase responses to stress. Also, analysis of the sea urchin embryonic kinome has revealed that $76 \%$ of the kinases are expressed during embryonic development and that general trends were consistent with that seen in other multicellular embryos (Bradham et al., 2006). For example, kinases involved in apoptosis were expressed at less than $50 \%$ in embryos compared to adults, corroborating previous studies that noted that apoptosis did not occur in embryos during the early phases of development (Vega and Epel, 2004; Vega-Thurber and Epel, 2007). A total of $88 \%$ of the signaling kinases were expressed during sea urchin embryonic development (Bradham et al., 2006), some of which may be acting as the regulatory controls for embryonic development during periods of stress.

The recent sequencing and annotation of the sea urchin genome has produced many insights and a large body of information about the genome (Bradham et al., 2006; Fernandez-Guerra et al., 2006; Goel and Mushegian, 2006; Goldstone et al., 2006; Howard-Ashby et al., 2006; Livingston et al., 2006; Sodergren et al., 2006). Specifically, the sea urchin genomic sequence has stimulated the production of a "tool set" from which to analyze marine organismal physiology and responses to stress (Hofmann et al., 2005). Proteomic studies of sea urchins can now be pursued to validate aspects of the functional genome. Analyses by Roux et al. (2006; 2008) provided a detailed proteomic survey of sea urchin eggs and zygotes in response to fertilization. These studies provide a better picture of the proteins that are present in the egg and immediately after fertilization as well as changes in their phosphorylation state. 
Goldstone et al. (2006) utilized the genome data to provide insights about the available chemical defensome including oxidative stress proteins involved in UVR response. The presence of these genes confirms the cellular studies revealing sea urchin embryos have a variety of defense mechanisms to continue embryogenesis in stressful environments, including the use of defense proteins (Hamdoun and Epel, 2007), but the actual proteins used to mediate UV-induced cell cycle delay have not been fully identified. A recent review on the molecular basis of the cellular stress response (CSR) may shed some light into the proteins mediating the general responses to macromolecular damage that lead to cell cycle delays (Kültz, 2005). The activation of the CSR is a general pathway launched by cells of all superkingdoms to cope with a variety of stressors including temperature, osmotic and UVR stress (Kültz, 2005). Proteins mediating the CSR in UV-stressed sea urchin embryos have not yet been identified, thus, a proteomic analysis can discover whether proteins in the CSR are expressed in sea urchin embryos and if they are changing in response to UVR. Identifying the proteins potentially involved in a sea urchin embryo CSR to UVR could provide further evidence for physiological biomarkers of UV-stress.

Proteomics, the study of global protein structure and function, has become an instrumental way to discover biomarkers of ecological stress in marine invertebrates (Hamer et al., 2004; Tomanek and Sanford, 2003). Two-dimensional SDS-PAGE gel electrophoresis (2D GE) combined with matrix assisted laser desorption- time of flight mass spectrometry (MALDI-TOF MS) is a powerful method for identifying changes in global protein expression patterns in response to environmental stimulus. By separating proteins in two dimensions (isoelectric focusing point, pI, and MW), surveys of the global expression of proteins in eggs and embryos of both normal and 
UVR stressed sea urchin embryos can be measured. Protein spots exhibiting changes in expression patterns then be positively identified using MALDI-TOF MS.

For nearly a century we have known that sea urchin embryos experience UVinduced delays in the early mitotic cycles after fertilization (Giese, 1938). To date, the molecular mechanisms mediating these delays have not yet been fully explained. This report provides the most comprehensive examination of how the majority of the sea urchin proteome responds to UV-irradiation to help resolve the long-standing question of what proteins and potential cellular pathways are altered during UVinduced cell cycle delays. A comparison of the proteomes from embryos exposed to and protected from UVR has the power to identify multiple proteins in multiple pathways and provides information from a global perspective to resolve the proteins involved in UV-induced cell cycle delays. Identification of these proteins will allow us to perform more targeted analyses of post-translational modifications that appear to be regulating or be regulated by UV-induced delays in division in sea urchin embryos. 


\section{Chapter 2-Manuscript}

\section{EXPOSURE TO ULTRAVIOLET RADIATION CAUSES PROTEOMIC CHANGES IN EMBRYOS OF THE PURPLE SEA URCHIN, STRONGYLOCENTROTUS PURPURATUS}

\section{Introduction}

Widespread release of ozone-depleting gasses over previous decades has led to reductions in Earth's ozone layer, increasing the total amount of ultraviolet radiation (UVR, 280-400 nm), particularly ultraviolet B (UVB, 280-320 nm) reaching Earth’s surface (Madronich et al., 1998; McKenzie et al., 2007; Smith et al., 1992; WMO, 2007). The majority of ozone depletion is in polar regions; nevertheless, moderate increases of UVB in temperate regions $(\sim 7 \%$ in the summer and $35 \%$ in the winter) suggest mid-latitude ecosystems may also be impacted (Kerr and McElroy, 1993). Despite reductions in the release of depleting gasses, ozone levels are not expected to return to 1980 levels in polar regions until approximately the year 2050 (Madronich 1998; McKenzie et al., 2003; 2007) and it is unclear whether levels of ozone will ever return to that seen before ozone thinning started in the 1970’s (McKenzie et al., 2007).

Moreover, recent reports emphasize that despite stabilization of ozone levels at temperate latitudes, UVB levels on Earth will continue to increase by a few percent per decade due to global climate change (McKenzie et al. 2003; 2007; WMO, 2007). The complex interactions among ozone depletion, climate change and UVR are mediated by multiple factors including atmospheric circulation patterns and atmospheric chemistry, and predictions for complete ozone stabilization are difficult to assess because changes in ozone can affect the climate, including cloud cover and 
albedo, while changes in climate can in turn affect changes in ozone (Häder et al., 2007; McKenzie et al., 2007; United Nations Environment Programme, Environmental Effects Assessment Panel, 2004; 2005). Also, changes in ocean temperature and $\mathrm{pH}$ can result in water stratification that has a profound effect on the amount of chromophoric dissolved organic matter (CDOM) that is photobleached by UVR (Anderson et al., 2001; Häder et al., 2007). The photobleaching of CDOM enhances penetration of UVR into the ocean and increases photooxidative damage to marine organisms (Zepp et al., 2003).

Harmful levels of solar ultraviolet A (UVA, 321-400 nm) and UVB penetrate as much as several meters in organically rich coastal seawater of temperate regions (Adams et al., 2001; Karentz and Lutze, 1990; Tedetti and Sempere, 2006). Even at the pre-ozone depletion levels, UVR stress is deleterious to molecular, biochemical and physiological functioning (Xiong et al., 1999) leading to reductions in total productivity of phytoplankton and zooplankton (Cullen and Neale, 1994; Williamson et al., 1994).

UVR is a driving force in both terrestrial and aquatic ecosystems, causing reductions in ecosystem function, alterations of trophic interactions, and results in mutation and altered cellular function in exposed organisms lacking UVR defenses (Caldwell et al., 1998 and Häder et al., 2007). Cellular targets such as proteins, DNA and lipids absorb light differently and may vary in UV-sensitivity. Exposure to UVB results in direct protein damage by photochemical degradation of tryptophan and tyrosine residues and destroys disulfide bonds required for protein-protein interactions (Hollósy, 2002; Tevini 1993). UVB damages DNA through the 
production of cyclobutane pyrimidine dimers (CPD's) among other photoproducts (Imlay and Linn, 1988; Lesser et al., 2003; Peak and Peak, 1990; Setlow 1974; Tevini 1993). UVA makes up greater than $90 \%$ of the total UVR that reaches Earth's surface and causes photooxidative damage through the production of reactive oxygen species (ROS) that rapidly oxidize nucleic acids, proteins and lipids (Pourzand and Tyrrell, 1999; Tyrrell 1991).

Embryos are the most sensitive life stage of aquatic organisms and echinoid embryos (including sea urchins) have been used extensively as a valuable model embryonic system for studying the effects of environmental factors such as temperature, oxidative stress, chemical pollutants and UVR (Adams and Shick, 1996; Bancroft et al., 2007;Lesser et al., 2003; Pesando et al., 2003; Russo et al., 2003). Sea urchins inhabit all of Earth's major oceans and have life history stages sensitive to UVR (Adams and Shick, 1996; 2001; Anderson et al., 1993; Lesser et al., 2003). Sea urchin embryos are an ideal system for studying effects of UVradiation on embryonic development and cells in general because they are easy to spawn, fertilize and culture in the laboratory and adults provide large amounts of gametes and embryos that divide synchronously, allowing for molecular and integrative physiological studies. More importantly, sea urchin embryos can be naturally fertilized and cultured in the lab under similar conditions found in the field since $S$. purpuratus are broadcast spawners.

The UV-sensitivity of sea urchin gametes and embryos is well studied; reductions in the times for cell division and abnormal development and morphogenesis have been observed in response to UVR (Adams and Shick, 1996; 
2001; Bonaventura et al., 2005; 2006). Specifically, exposure of eggs and early embryos to UVR causes delayed completion of the first mitotic division with embryos stalling at prophase in the cell cycle (Adams and Shick, 1996; 2001; Giese, 1964; Rustad, 1971). Although many sea urchin species have been used to examine effects of UVR, embryos from the purple sea urchin Strongylocentrotus purpuratus are ideal to examining the effects of UVR for a variety of reasons.

Recently the S. purpuratus genome was sequenced, and the repertoire of genes expressed in eggs and during embryogenesis, the embryonic transcriptome, was analyzed, providing powerful tools for analyzing effects of UVR on this model species (Samanta et al., 2006; Sodergren et al., 2006). S. purpuratus has been an instrumental model organism for studies that detail the genes used in biomineralization (Livingston et al., 2006) and intermediary metabolism (Goel and Mushegian, 2006), which are actively regulated during development and differentiation (Howard-Ashby et al., 2006). Sequencing of the genome also allowed a more extensive identification of the regulatory protein kinases constituting the Kinome during early development (Bradham et al., 2006) and the sea urchin complement of proteins used for cell cycle control (Fernandez-Guerra et al., 2006). Moreover, the genomic sequence provided information about the number of proteins that are in the sea urchin genomic arsenal for chemical defense, including those known to be important in responding to UV-induced oxidative stress in other organisms (Goldstone et al., 2006). These initial surveys of the genome provide a great deal of insight for the potential genetic regulation of basic sea urchin development in non-stressed conditions, but functional analysis, especially during stress have yet to be conducted. 
Responses to stress involve coordinated cellular signaling including the control of the cell cycle, metabolism, transcription regulation, development and differentiation, apoptosis, and other cellular functions. Importantly, studies have specifically documented the production of CPD's in UVR-stressed sea urchin embryos (Lesser et al., 2003; 2006). These experiments highlight DNA damage as contributing to UVR stress, but interestingly, the action spectra for sea urchin division delays caused by UV-irradiation of eggs and embryos are more similar to protein absorption rather than just DNA absorption (Giese, 1964). Amino acids absorb UVR, therefore UVR stress is not only the result of DNA damage, but likely also affects protein components in sea urchin embryos.

Sea urchin embryos have a variety of defense mechanisms to continue embryogenesis in stressful environments including rapid cell division and the evolution of a "be prepared" strategy, which includes selective packaging of defense proteins in embryos to combat stressful, yet unknown, environmental fluctuations in toxic chemicals, heavy metals and during periods of redox flux (Hamdoun and Epel, 2007). Examples of these proteins include Cytochrome P450, heat-shock proteins (HSPs) and efflux transporters (Hamdoun and Epel, 2007). A recent review on the molecular basis of the cellular stress response (CSR) conserved in all organisms provides insight into the proteins mediating the general responses to macromolecular damage that lead to cell cycle delays (Kültz, 2005). The activation of the CSR is a general pathway launched by cells from all superkingdoms to both sense macromolecular damage and to cope with a variety of stressors including temperature, osmotic and UVR stress (Kültz, 2005). Proteins affected by UVR and involved in either cleavage delay or the CSR in UV-stressed sea urchin embryos have 
not yet been comprehensively identified, thus, a proteomic analysis can discover which proteins of the CSR are expressed in embryos and if they are changing in response to UVR. Identifying the proteins potentially involved in the sea urchin CSR to UVR could provide further evidence for establishing physiological biomarkers of UV-stress.

Proteomics, the study of global protein structure and function, has become an instrumental way to discover biomarkers of ecological stress in marine invertebrates (Hamer et al., 2004; Tomanek and Sanford, 2003). Two-dimensional SDS-PAGE gel electrophoresis (2D GE) combined with matrix assisted laser desorption- time of flight mass spectrometry (MALDI-TOF MS) is a powerful method for identifying changes in global protein expression patterns in response to environmental stimuli. By separating proteins in two dimensions (isoelectric focusing point, pI, and MW), surveys of the global expression of proteins in eggs and embryos of both normal and UVR stressed sea urchin embryos can be measured. Expression pattern changes in individual protein spots are found on 2D GE gels and the proteins spots can be positively identified using MALDI-TOF technology.

It has long been known that sea urchin embryos experience UV-induced delays in the early mitotic cycles after fertilization (Adams and Shick1996; Rustad, 1971). However, the complete mechanisms mediating these delays have not yet been elucidated. In this report, we provide the most comprehensive examination of how the majority of the sea urchin proteome responds to UV-irradiation to help resolve the long-standing question of what proteins and potential cellular pathways are altered during UV-induced cell cycle delays and utilize the insights of the sea urchin genome 
sequence (Bradham et al., 2006; Goldstone et al., 2006; Samanta et al., 2006;

Sodergren et al., 2006) to present the first description of how UVR can affect multiple proteins in multiple cellular pathways simultaneously. By using a comparative proteomic survey of UV-treated and UV-protected batches of sea urchin embryos we present the identification of 143 proteins exhibiting differential UV-induced expression patterns. This comparison will allow us to perform targeted analyses of post-translational modifications that appear to be regulating or be regulated by UVinduced delays in division in sea urchin embryos and compile a list of protein biomarkers for UV-associated cell death and disease states. 


\section{Materials and Methods}

\section{Sea urchin collection, gamete gathering and embryo culture: Adult}

Strongylocentrotus purpuratus, were collected from Goleta, California in November 2007 and held at $10^{\circ} \mathrm{C}$ in re-circulating seawater aquaria. Sea urchins were induced to spawn using intracoelomic injections of $0.55 \mathrm{M} \mathrm{KCl}$. Eggs from six females were collected separately in $0.22 \mu \mathrm{m}$ filtered seawater (FSW) between $13-15^{\circ} \mathrm{C}$, diluted to $5 \%(\mathrm{v} / \mathrm{v})$, washed three times with FSW and treated with $1 \mathrm{mM}$ ammonium triazole (ATAZ) to prevent hardening of the fertilization envelope. Eggs were fertilized using a 1:50,000 dilution of dry sperm from a single male and embryos were cultured in FSW between $13-15^{\circ} \mathrm{C}$ during UVR exposure. All cultures achieved at least $95 \%$ fertilization.

UVR-exposure and quantification: Batches of embryos $(\mathrm{n}=6)$ were exposed to or protected from artificial UVR using UVA-340 lamps (Q-Panel Lab Products, Cleveland, OH, USA) that simulate the solar spectrum of UVR (as in Adams and Shick, 2001; see Shick 1999 for lamps spectral signature). These lamps provide a means to study cellular targets and molecular mechanisms of UV-induced damage, by providing consistent doses at a set range of wavelengths. Embryos were exposed to either photosynthetically active radiation (PAR, 400-700nm, UV-protected) using UV-opaque acrylic cover (Plexiglas UF3, Arkema, Philadelphia, PA, USA, 50\% cutoff at $400 \mathrm{~nm})$, or PAR + UVA + UVB (295-700nm, UV-treated) using UVtransparent acrylic cover (Plexiglas G-UVT, Arkema, 50\% cutoff at $290 \mathrm{~nm}$ ) over 9 $\mathrm{mm}$ glass Petri dishes containing a monolayer of embryos. 
UVA and UVB irradiance was measured during UVR exposures using an IL 1400A radiometer coupled with a UVA sensor (model SEL033) or UVB sensor (model SEL240) with maximal peak sensitivities at $350 \mathrm{~nm}$ and $295 \mathrm{~nm}$ respectively (International Light, Newburyport, MA, USA). Average measured UVA-irradiance was $1.11 \mathrm{~mW} / \mathrm{cm}^{2}( \pm 0.02$ s.e.m) and UVB-irradiance was 0.04 $\mu \mathrm{W} / \mathrm{cm}^{2}( \pm 0.001$ s.e.m).

Embryos were exposed to UVR for either 25 min (“30 min” samples, see below) or 60 min (known to cause cleavage delay but not death as per Adams et al. 2009 in preparation, "90 min" samples, see below) after fertilization. Embryos exposed to UVR for 25 min experienced cumulative UVA and UVB doses of $16.62 \mathrm{~kJ} / \mathrm{m}^{2}$ and $0.60 \mathrm{~kJ} / \mathrm{m}^{2}$ respectively (total UVR dose was $17.22 \mathrm{~kJ} / \mathrm{m}^{2}$ ). Embryos exposed to UVR for 60 min experienced cumulative UVA and UVB doses of $39.90 \mathrm{~kJ} / \mathrm{m}^{2}$ and $1.43 \mathrm{~kJ} / \mathrm{m}^{2}$ respectively (total UVR dose was $41.33 \mathrm{~kJ} / \mathrm{m}^{2}$ ). UV-exposure experiments included PAR illumination to allow photorepair in UV-exposed embryos. Gentle resuspension of cultures was performed every 10 min during exposure.

Protein lysate preparation: Lysates were prepared at two time points (30 min and $90 \mathrm{~min}$ ). Embryos were sampled at 30 min post-fertilization because irradiation of sea urchin eggs and early embryos prior to 30 minutes post-fertilization results in developmental retardation but does not affect DNA synthesis (Adams et al., 2009 in preparation, Rao and Hindgardner, 1965; Zeitz et al., 1968). Lysates were also prepared at 90 min post-fertilization just prior to the onset of mitosis in UVprotected embryos. Embryos were lysed on ice using a $27 \mathrm{G}$ needle in a $0.1 \%$ 
TritonX-100 lysis buffer containing protease and phosphatase inhibitors $(0.1 \%$ TritonX-100, 15 mM disodium EGTA, $150 \mathrm{mM} \mathrm{NaCl,} 20 \mathrm{mM}$ HEPES pH 7.0, 60 $\mathrm{mM} \beta$-glycerolphosphate, $0.5 \mathrm{mM} \mathrm{Na}_{2} \mathrm{VO}_{4}, 1 \mathrm{mM} \mathrm{NaF}$, Roche CompleteMini PIC). Lysates were kept on ice for 20 min and centrifuged at 14,000 rpm. Lysates were immediately snap frozen using liquid nitrogen and stored at $-80^{\circ} \mathrm{C}$ until analysis.

Developmental delay assays: In parallel, embryos from each batch were preserved in $1 \%$ formalin buffered FSW every 10 min post-fertilization until completion of the first mitotic division. At least, 200 embryos from each sample were scored for cell division and the percentage of cleaved embryos was calculated. A random complete block design (RCBD) ANOVA was performed to assess effects of UVtreatment on the timing of development to $50 \%$ of each batch to complete cleavage for factors of UV-treatment and blocked by batch of eggs. The degree of UVinduced delay in division for all six batches of embryos was determined and percentage cleavage delay (PCD) was calculated for each batch using the following equation (Eqn 1):

$P C D=\frac{\text { Time for } 50 \%\left(T_{50}\right) \text { of UV-treated embryos to divide }-T_{50} \text { of UV-protected embryos to divide }}{T_{50} \text { of UV-protected embryos to divide }}$

Protein quantification and 2D GE: Protein concentrations were determined using the BCA microplate method (Pierce Biotechnology, Rockford, IL, USA) according to the manufacturer's instructions. A total of $100 \mu \mathrm{g}$ of TritonX-100 soluble protein was denatured in DeStreak Rehydration Solution (GE Healthcare, Piscataway, NJ, USA) and passively rehydrated into $\mathrm{pH}$ 4-7 isoelectric focusing (IEF) strips (GE 
Healthcare) according to manufacture's instructions. First dimension isoelectric focusing of proteins was performed for 21.8kVhrs on a GE Healthcare Ettan IPGphor3 IEF System using the following method: gradual increase from 0 to 0.5 kilovolts (kV, $2 \mathrm{hrs}), 0.5$ to $1 \mathrm{kV}(1 \mathrm{hr}), 1$ to $6 \mathrm{kV}(2.5 \mathrm{hr})$, held at $6 \mathrm{kV}(2 \mathrm{hr})$. Strips were immediately equilibrated first in a $1 \%$ DTT/equilibration buffer $(6 \mathrm{M}$ urea, $75 \mathrm{mM}$ Tris $\mathrm{HCl}, 29.3 \%$ glycerol, $2 \%$ SDS, $0.002 \%$ bromophenol blue) and then in a $4 \%$ Iodoacetamide/equilibration buffer. Proteins were separated by molecular weight using 10\% SDS-PAGE on a BioRad (Hercules, CA, USA) Criterion Deodca system. One gel was run for each batch of embryos for each treatment at each time-point (six batches of embryos, two UV-treatments at two time-points for a total of 24 gels). To minimize gel-to-gel variation between UVR treatments of the same batch of embryos, 2D GE for all 30 min UVR treated and protected lysates and all 90 min lysates were run simultaneously in the first and second dimension. Preliminary analysis showed low gel-to-gel variation among triplicate gels using lysate from a single batch of sea urchin embryos protected and exposed to UVR.

Protein detection and image analysis: Proteins in gels were fixed in $7 \%$ glacial acetic acid/50\% methanol and stained with SYPRO Ruby stain (Invitrogen, Carlsbad, CA, USA) according to manufactures instructions. Proteins were detected using a Typhoon Trio+ Imager (GE Healthcare, Piscataway, NJ, USA) using a 532 $\mathrm{nm}$ bandpass filter at $525 \mathrm{pmt}$ voltage and a laser path of 50 microns.

All gel images were warped to a composite image (proteome map), which was used to detect spots that were subsequently transferred to the original gel 
images using Delta2D software (version 4.0, Decodon GmbH, Greifswald, Germany), using a similar workflow to that described in Berth et al., 2007. Briefly, Delta2D software was used to perform image warping. Warping creates exact and informed landmark spot matches among gel images and results in proteome maps that contain the necessary positional information to remove spot position variation among all gel images and allowed direct comparisons of all 24 raw $2 \mathrm{D}$ gel images. A fused master proteome map containing all spots within all $242 \mathrm{D}$ gels from all batches at all time points and UV-treatments was created digitally and used to represent all gel images within a single figure. Spot boundaries for all spots were designated on the master proteome map and because the total proteome map was a compilation of all 24 gel images, it offered the advantage of accurate spot detection and quantification across all raw gel images.

Spots on raw gel images containing all specified spot boundaries were then quantified as pixel density. The pixel density for each spot was normalized within each gel image to quantify the percent volume of each spot. The percent volume represented spot expression density and was used to compare protein spots across gel images. Further, a fusion image was compiled digitally to create a visual representation of all six batches for each time point at each UV-treatment.

Differential normalized spot densities were analyzed using the Delta2D integrated The Institute for Genomic Research Multi Experiment Viewer software (TIGR MeV, version 4.0, see Saeed et al., 2003). A 2-way ANOVA for each spot (with 2000 permutations of raw data from original gel images) was performed to identify significant differences in protein expression between UV-treatments and 
among individual batches for each time point at $\mathrm{P} \bullet 0.03$. An $\alpha=0.03$ was selected to reduce the number false spots showing differential regulation by UVR. Although the statistical power to analyze the differences between time points existed using this experimental design, a 3-way ANOVA could not be performed in the TIGR $\mathrm{MeV}$ software to remove any significant effect of individual batch. Delta2D software further doesn't allow for analysis of covariance of spots between gel images. Furthermore, comparisons between the 30 and 90 minutes time points were not performed because of the differences in total UVR dose between the two time points. For these reasons the analysis was limited to a 2-way ANOVA for factors of UV-treatment and blocked by the factor of individual batch of sea urchin embryos at each time point. Preliminary analysis using the above method indicated low gelto-gel variation between 2D gels from the same lysate run on triplicate gels.

Protein spot picking, digestion and MS analysis: Protein spots were excised from gels using a BioRad ProteomeWorks automated spot picker from two different 2D gels. Spots from two different gels were combined after imaging and statistical analysis of gels and was required to obtain a critical amount of protein from $2 \mathrm{D}$ gels. Each spot was then digested with $82 \mathrm{ng}$ of trypsin (Promega, Madison WI, USA) and the resulting peptide fragments were spotted on an Anchorchip ${ }^{\mathrm{TM}}$ metal target (Bruker Daltonics Inc.) using -cyano-4-hydroxycinnamic acid (HCCA). Matrix Assisted Laser Desorption Ionization-Tandem Time of Flight Mass Spectrometry (MALDI-TOF-TOF MS, Ultraflex III, Bruker Daltonics Inc., Billerica, MA, USA) was used to identify proteins. Tandem mass spectrometry (MS/MS) was performed on at least four of the most abundant peaks found in the original mass spectrum (MS). 
To confirm spot identities, the resulting spectrum were analyzed using the Biotools software suite (version 3.1, Bruker Daltonics Inc.). Each spectrum was internally calibrated using at least two trypsin autolysis peaks. Resulting peptide fragment molecular weights from both the MS and MS/MS were then searched against an in-house database created using MASCOT software (www.matrixsciences.com) containing all known sequences from S. purpuratus (obtained from NCBI in January 2009). Searches were performed using the MOlecular Weight SEarch (MOWSE) method modified by MASCOT (see Perkins et al., 1999). Proteins with a MOWSE score was exceeding a certain threshold value, that is database dependent, indicated the protein identification was significant at $\mathrm{P}<0.05$. Minimum criteria were set as an incomplete trypsin digestion with peptide mass tolerances at $1 \mathrm{Da}$ and MS/MS mass tolerances at $0.7 \mathrm{Da}$. Both carbamidomethylation of cysteine and oxidized methionine were set as variable modifications. All identifications represent significant MASCOT MOWSE scores set at a threshold of $=0.05$.

Expression volumes for all protein spots identified by mass spectrometry were standardized for each spot across all batches of embryos. Both standardized protein spot expression density and embryo batch were hierarchically clustered using a Pearson correlation. Support for clustering protein expression patterns was analyzed by bootstrap analysis. 


\section{Results}

Effects of UVR on mitosis: As expected (c.f. Adams and Shick, 1996), moderate ecologically relevant UV-treatment resulted in delayed cleavage for all batches of embryos after a 60 min UVR treatment $(\bar{x}=23.24 \min \pm 1.92$ s.e.m, Fig. 1$)$. The UVR dose and time of exposure was specifically chosen to delay embryos and not to adversely affect subsequent development. Figure 1 shows the mean percent cleavage for all six batches of embryos from UV-protected and exposed treatments as a function of time post-fertilization. The time for $50 \%$ of the embryos to divide was significantly delayed by UV-treatment $(\mathrm{P}<0.0001)$ and varied significantly by batch $(\mathrm{P}=0.031)$. There was no interaction between UVR treatment and embryo batch and UV-treatment resulted in delayed cleavage for all batches. Fifty percent of UVprotected embryos cleaved between $110 \mathrm{~min}$ and $122 \mathrm{~min}$, whereas $50 \%$ of embryos from the same batches treated with a $41.31 \mathrm{~kJ} / \mathrm{m}^{2}$ cumulative dose of UVR cleaved between $133 \mathrm{~min}$ and $154 \mathrm{~min}$.

The rate of division for each set of eggs from all females varied slightly, therefore the percent delay was calculated for each batch (Eqn 1) to standardize across embryos from all females. Batches of embryos on average suffered a $19.93 \%$ ( \pm 1.53 s.e.m.) UV-induced delay in mitosis. Remaining UV-protected and UVtreated batches of embryos were cultured at $15^{\circ} \mathrm{C}$. Although observations of mortality were not assessed, all batches of embryos from both UV-treatments appeared to be at the swimming hatched blastula stage within 24 hours post-treatment and no obvious morphological differences were detected. 


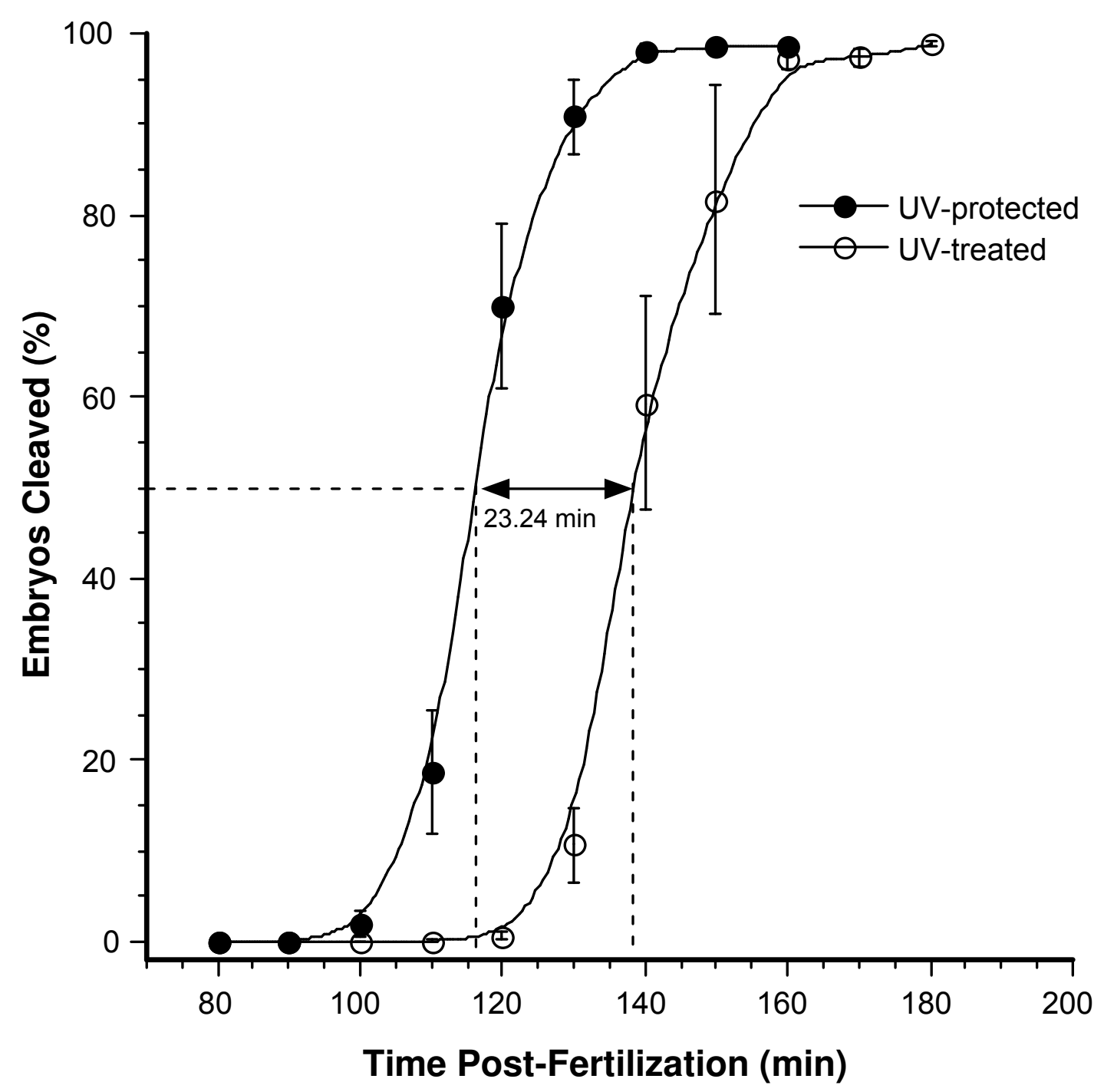

Fig.1. Graph of mean ( \pm s.e.m) cleavage rates from UV-protected and UV-treated $S$. purpuratus embryos ( $\mathrm{n}=6$ batches) at $10 \mathrm{~min}$ intervals starting at 80 min postfertilization through the completion of the first mitotic cell cycle $(n=200$ embryos counted for each of six batches for each time point). Embryos were UV-treated $(O)$ or UV-protected () from a total dose of $41.31 \mathrm{~kJ} / \mathrm{m}^{2}$ UVR $(290-400 \mathrm{~nm})$ delivered over a period of $60 \mathrm{~min}$. Smooth curves were fit to data points (black lines) and dashed lines identify the average time required for $50 \%$ of embryos to cleave for each treatment. $\leftrightarrow$ indicates the average UV-induced delay in cleavage to be $23.24 \mathrm{~min}$. 
Differential spot migration: Embryos were fertilized and exposed to UVR for 25 min and 60 min to create protein lysates at 30 and 90 min respectively. Figures $2 \mathrm{~A}$ and 2B display color overlaid average proteome maps of the 30 min and 90 min postfertilization batches (UV-protected lysates are colored blue, UV-treated lysates are orange and the spots that exhibit overlay are shown a dark gray to black). Using the total fusion proteome map described previously, 1,306 spot boundaries were established. Observing the 2D gel images using both digital image fusion and treatment image overlays allows for a visual inspection of the overall effect of UVR on the sea urchin embryonic proteome, but can be misleading. These overlays were not analyzed specifically because even though great care and effort was taken to minimize incorporating experimental errors in UVR treatment, lysate preparation, creation of the 2D gels and image warping, these are average images from embryos developing at slightly different rates. These techniques for creating total and time point specific image fusions rather served as reference gel images to depict the results of statistical analyses by providing a single image of all batches at all UV-treatments for each time point. 


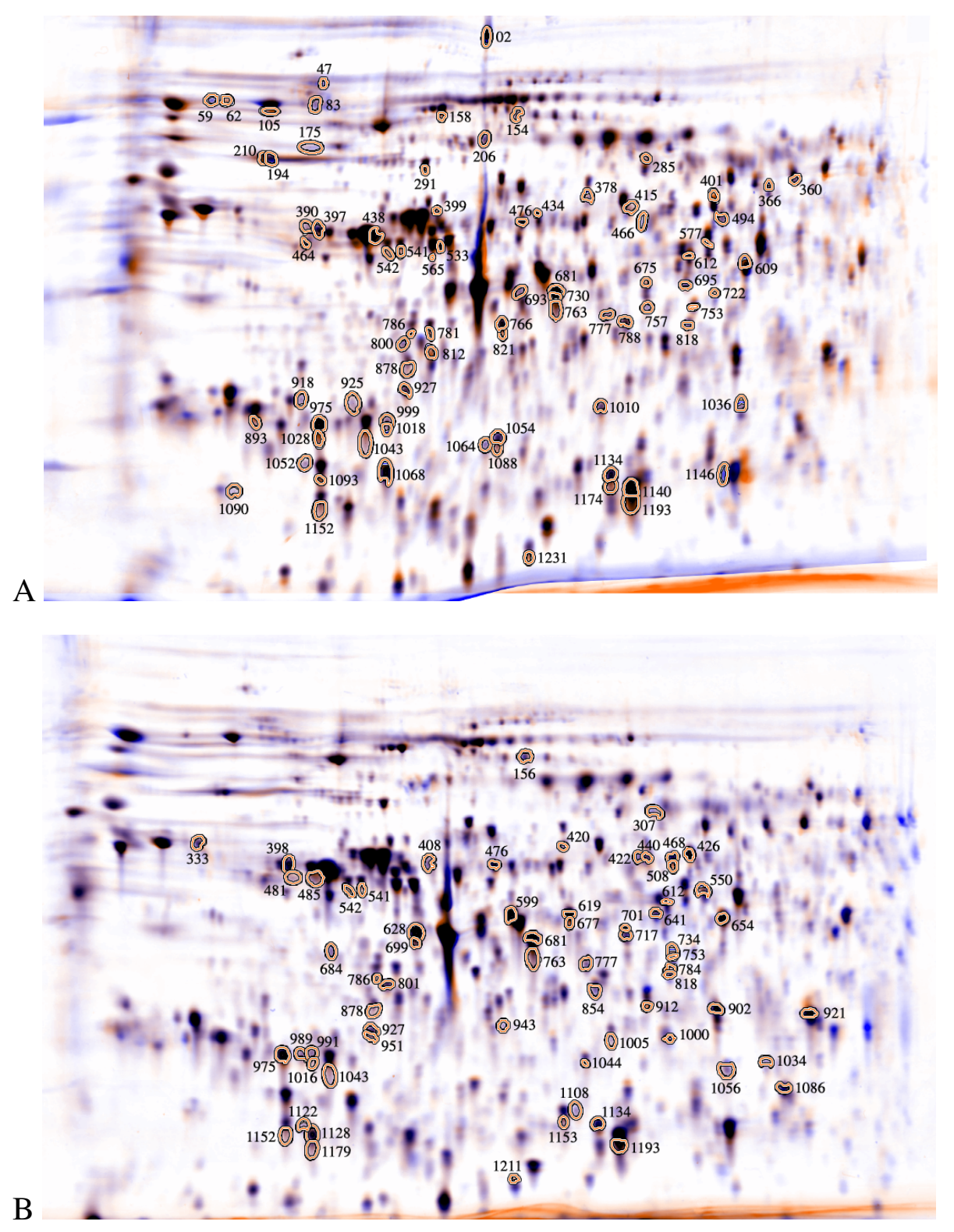

Fig. 2. Overlay of fusion averaged 2D gel images (proteome maps) for six batches of $S$. purpuratus embryos. Colored spots represent proteins from lysates from different UVR treatments [UV-protected (blue), UV-treated (orange) and overlap (black)]. Highlighted and numbered protein spots correspond to table 1 as spots that migrate differently due to UVR treatment and identified by MALDI-TOF MS + MS/MS. (A) Overlay of proteome profiles for embryos at $30 \mathrm{~min}$ post-fertilization either protected from or exposed to a total of $17.21 \mathrm{~kJ} / \mathrm{m}^{2} \mathrm{UVR}$ ( $\mathrm{n}=12$ gels, 6 for each UV-treatment). (B) Embryos at 90 min post-fertilization either protected from or exposed to a total of $41.31 \mathrm{~kJ} / \mathrm{m}^{2}$ UVR. Each overlay contains 12 2D gel images per time point. All six batches are represented in each treatment at each time point in both $\mathrm{A}$ and $\mathrm{B}$. 
A 2-way ANOVA for each spot was performed on normalized spot volume values from all gel images for factors of batch and UV-treatment at each time point ( $=0.03)$. At least 171 protein spots ( $13 \%$ of the total proteome) showed differential spot volumes across each batch of embryos for UV-treatment at $30 \mathrm{~min}$ postfertilization. At 90 min post-fertilization, a total of 187 spots ( $14 \%$ of the proteome) were differentially regulated between UV-treated and UV-protected batches of embryos. Individual batch variation was quantified as a blocking factor in the 2-way ANOVA between each batch for each time point. At $30 \mathrm{~min}, 281$ spots ( $21 \%$ of the proteome) varied among batches, whereas 390 spots (30\% of the proteome) varied among batches at 90 min post-fertilization. Although there is a high variation in spots among individuals, performing the ANOVA with a block by embryo batch ensured that the most consistent spots among batches that migrated differently due to UVirradiation were identified.

Although the dynamics of protein spots that show differential migration as a result of UVR can be tracked using a proteomic approach, changes in individual protein spot abundance are not presumed to be from protein turnover or new translation and may be a result of either post-translational modifications (PTMs), extracellular efflux or organelle localization. It is not possible to accurately and consistently distinguish among these on any one spot using the current method and therefore a spot exhibiting differential migration because of PTM or efflux was then broadly classified as being differentially regulated. Regardless of a protein spot moving from one part of the gel to another, protein translation or protein turnover, all are encompassed in one term and represent at least one of these process occurring. 
MALDI-TOF-TOF protein identifications: First, differentially regulated protein spots among UV-treatments identified above were selected for MS analysis. Second, spots from this list also had to be abundant enough ( $>0.005$ percent volume in raw 2D images) for high quality MS/MS spectra on at least the four most abundant fragments found in the MS spectrum. Therefore, a total of 176 protein spots were selected for identification, 94 for $30 \mathrm{~min}$ and 82 for $90 \mathrm{~min}$ post-fertilization.

All but 33 protein spots were identified using the minimum threshold of a significant MOWSE score for combined MS and MS/MS spectra searched against the predicted $S$. purpuratus proteome ( $\mathrm{P}<0.05$, Fig. 2A and 2B, Table 1). Proteins identified by MS + MS/MS are outlined and labeled in Figures $2 \mathrm{~A}$ and $2 \mathrm{~B}$ and numbers associated with each spot relate to the identifications in table 1.

Table 1 provides details for identified proteins by UV-treatment and time point. Specifically noted are the names of the proteins for all positive MALDI-TOF identifications. Theoretical molecular weight and isoelectric focusing points are provided along with the $S$. purpuratus NCBI blastp accession number for the highest MOWSE score for the top protein result. Furthermore, the average relative foldchange in spot volume between UV-treated and UV-protected lysates is designated. The relative fold changes are an average of all normalized spot volumes from the UVtreated batches divided by that of the same spot from the UV-protected batches. This information is valuable to indicating the amount of average protein spot change occurring after UV-treatment and further indicates the possible degree of sensitivity to UVR or regulation during the developmental program. 
By using the proteome map to set the spot boundaries first and then second transfer these to all spots on all gel images, spot consistency between gel images was accurately maintained between all combinations of raw 2D gels. Each spot was arbitrarily assigned a spot number on the total fusion proteome map so that each spot was re-established with the same number on each raw gel image. In many cases, the same spot number across gels resulted in identical protein identifications. Also, identical protein identifications were made for different spot numbers between the treatments and among the time points. This shows highly repeatable and reliable identifications using MALDI-TOF-TOF to identify S. purpuratus proteins that are tracked as a protein spot shifting between the UV-protected or UV-treated gels. For example at 30 min post-fertilization, spot number 210 exhibited elevated expression in UV-protected lysates and spot number 194 had elevated expression in the UVtreated lysates. Both of these spots were identified as HSP70. Also, spot number 1043, which was identified as 14-3-3 protein homolog 2, was identified multiple times from multiple gels and therefore showed complex regulation within the UVprotected 2D gels at 30 min and 90 min post-fertilization. 


\begin{tabular}{|c|c|c|c|c|c|}
\hline UV- Treatment' & Protein Identification & $\begin{array}{c}\text { Spot } \\
\text { Number }\end{array}$ & NCBI Accession & $\begin{array}{l}\text { Theorretical Mass } \\
\text { (kDA)/pl }\end{array}$ & $\begin{array}{c}\text { Fold Change } \\
\text { (Ireated/Protected) }\end{array}$ \\
\hline \multicolumn{6}{|l|}{ Trented-30 $\mathrm{min}$} \\
\hline & 14-3-3 like protein 2 & 1018 & XP_780530.1 & $31712 / 4.95$ & 1.414 \\
\hline & 14-3-3-like provein 2 & 1043 & $X P 780530.1$ & $31712 / 4.95$ & 1.772 \\
\hline & 1433_CANAL 14-3-3 protein homolog isoform 1 & 1028 & $\mathrm{XP}-780278.1$ & $28484 / 4.82$ & 1.763 \\
\hline & Adenosine kinase $\mathrm{A}$, isoform 1 & 781 & $\mathrm{XP}_{7} 780906.2$ & $44506 / 525$ & 1.617 \\
\hline & Adenusine kinase $\mathrm{A}$, isofjom 1 & 786 & $\mathrm{XP}_{7} 780906.2$ & $44506 / 5.25$ & 1.751 \\
\hline & Beta tubulin & 438 & XP 002161860.1 & $50084 i 4.73$ & 1.801 \\
\hline & CG7820-PA (Carbonic Anhydrase) & 1036 & XP_782997.2 & $29667 / 5 \mathrm{R8}$ & 1.552 \\
\hline & CG8649-PC (Calponin homology) & 291 & $\mathrm{XP}=01181280.1$ & $51764 / 550$ & 1,93 \\
\hline & EXSANGPO0000027279, partial & 812 & XP_793193.2 & $30363 i 5.07$ & 2.379 \\
\hline & Fukaryotic translation initiation factor 2 , subunit 1 alpha, $35 \mathrm{kDa}$ isoform I & 878 & XP_779939.1 & $35599 / 4.95$ & 1.206 \\
\hline & Gelsolin & 609 & $X^{2}-001176123.1$ & $40308 / 5.91$ & 1.967 \\
\hline & Gk2-prov protein, partial & 434 & XP_785650.2 & 5473715.70 & 2.016 \\
\hline & Glutamine synthetase, isoform 2 & 763 & $\mathrm{XP} 801741.2$ & $38792 i 5.68$ & 1.561 \\
\hline & Glutamine synthetase, isoform 2 & 730 & $\mathbf{X P}-801741.2$ & $38792 / 5.68$ & 1.337 \\
\hline & 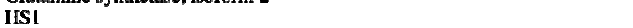 & 1093 & XP_788276.1 & $28685 / 4.89$ & 1.551 \\
\hline & HSP70 isnform 3 & 210 & $\mathrm{XP}-802057.1$ & $71816 / 5.32$ & 1.82 \\
\hline & Hypothetical protein (RPA2_OBF_fanily), partial & 285 & XP_001201004.I & $49967 / 525$ & 1.575 \\
\hline & Ilypotherical protein (Chaperonin superfamily) & 378 & XP_785987.2 & $47221 / 708$ & 1.352 \\
\hline & Hypothetical protein (DAHP synthase family) & 722 & $X P_{-783181.2}$ & $33458 / 5.84$ & 3.903 \\
\hline & Hypothetical protein (Proteasome alpha type 3) & 1088 & $\mathrm{XP}_{1} 796247.2$ & $28253 / 5.61$ & 1.477 \\
\hline & Hypotherical protein (Ubiquitin region) & 415 & $\mathrm{XP}-793278.2$ & $42012 / 5.49$ & 1.681 \\
\hline & Initiation factor 4AII isoform 11 & 542 & SP_001091916 & $47779 / 5.39$ & 1.772 \\
\hline & Initiation factor 4All isoform I] & 54] & XP_001091916 & $47779 / 539$ & 1.653 \\
\hline & Intermediate Chain 1 & 62 & $\mathrm{XP}=786989.1$ & $89183 / 4.46$ & 1.87 \\
\hline & Nuclear matrix protein NMP200 & 366 & XP_001204254.I & $42382 / 6.18$ & 1.958 \\
\hline & Nucleolin & 105 & XP_797746.2 & $43412 / 4.60$ & 2.061 \\
\hline & Peptidylprolyl isomerase D (Cyclophilin D) & 675 & XP_001201326.1 & $41650 / 607$ & 2.494 \\
\hline & Proleasome (prusorne, macropain) 26S subunit, non ATPase, 13, partial & 821 & XP_001197629.1 & $23219 / 5.07$ & 1.796 \\
\hline & 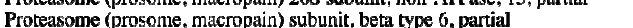 & 1231 & XP 001184184.1 & $23447 / 528$ & 2.741 \\
\hline & Proteasome alpha 2 subunit & 1174 & XP_001199987.1 & $7330 / 9.01$ & 1.632 \\
\hline & Proteasome alpha 5 subunit & 11.52 & XP_782337.1 & $26396 / 4,90$ & 1.381 \\
\hline & S-crystallin SL1I (major lens polypeptide), partial & 1193 & XP 001183993.1 & $1325 ! 1521$ & 2.139 \\
\hline & Smooth muscle myosin heavy chain 11 isoform SM1 like & 401 & $\mathrm{XP}_{7} 794940.2$ & $88008 / 733$ & 2.509 \\
\hline & 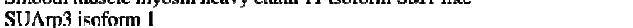 & 577 & $\mathrm{XP}-780265.1$ & $47113 / 5.81$ & 1.434 \\
\hline & Translaion elongation factor 1B alpha subunit isoform I & 893 & $\mathrm{XP}-780033.1$ & $23540 / 4.48$ & 1.548 \\
\hline & $\begin{array}{l}\text { Translationally controlled tumor protein } \\
\text {. }\end{array}$ & 1058 & $\mathrm{XP} 795619.2$ & $22249 ; 4.94$ & 1.198 \\
\hline & $\begin{array}{l}\text { Tubulin, alpha } 2 \text { isoform } 2 \\
\text { The }\end{array}$ & 399 & XP 001178868.1 & $50279 / 4.91$ & 1.1757 \\
\hline & Valosin containing protein isoform 2 , partial & 158 & XP_801708.2 & $59565 / 4.87$ & 2.395 \\
\hline & $\begin{array}{l}\text { Vasa homolog } \\
\text {. }\end{array}$ & 154 & $\mathrm{XP}-781494.2$ & $79972 i 6.05$ & 1.27 \\
\hline \multicolumn{6}{|c|}{ Protected-30 min } \\
\hline & 14-3-3 like protein 2 & 999 & XP_780530.1 & 317124.95 & -1.337 \\
\hline & 1433_CANAL 1433 prolein homolog isoform 1 & 975 & XP_780278.1 & $28484 / 4.82$ & 1.141 \\
\hline & 265 proteasome subunit p44.5 & 612 & $\mathrm{XP}-792957.1$ & $46703 i 5.75$ & -1.309 \\
\hline & $34 / 67 \mathrm{kDa}$ laminin binding protein & 464 & $\mathrm{XP}_{-} 792396.2$ & $18792 / 8.93$ & -1.671 \\
\hline & Actim CyIIIb & 2 & NP_999692.1 & $41805 / 522$ & 2.715 \\
\hline & Apolipoprotein B & 466 & $\mathrm{XP}_{8} 800206.2$ & $201488 / 6.08$ & $-2,413$ \\
\hline & Bisphosphatc nucleotidasc & 777 & XP_785239.1 & $33373 / 537$ & -1.258 \\
\hline & CCR4 NOT transeription complex, subunit 7 & 925 & XP 786386.1 & $32555 / 4.91$ & 1.198 \\
\hline & CG J0540-PA (F-actin capping protein) & 1050 & XP 001176707.1 & $32513 / 5.60$ & -134 \\
\hline & Fructose-1,6-bisphosphatise 1 & 788 & XP_793452.2 & $38058 / 5.82$ & -1.187 \\
\hline & GI to $S$ phase transition I & 206 & XP_785469.2 & $63845 / 5.11$ & 1.237 \\
\hline & GA10247-PA (ribonucleoprotein domain) & 494 & $\mathrm{XP}_{0}^{-101191771.1}$ & $53156 / 5.98$ & -1.304 \\
\hline & $\begin{array}{l}\text { Gelsolin } \\
\text { S }\end{array}$ & 565 & $\mathrm{XP}-792912.2$ & $41202 / 5.13$ & -1.466 \\
\hline & Glutunine synthetuse isoforn 2 & 693 & $\mathrm{XP}-801741.2$ & $38792 / 5.68$ & 1.165 \\
\hline & Glutamine synthetase isoform 2 & $68 \mathrm{~B}$ & $\mathrm{XP}-801741.2$ & 3879215.68 & -1.373 \\
\hline & Glutathione peroxidase, partial & 1146 & XP_784500.2 & $21013 / 7.00$ & -3.720 \\
\hline & GTP-binding protein & 83 & XP_99645.1 & $28001 / 4.72$ & -1.224 \\
\hline & HSI & 1052 & $X P 788276.1$ & $28685 i 4.89$ & -1.3 \\
\hline & HSP70 isoform 3 & 194 & XP_802057.1 & $71816 / 532$ & -1.328 \\
\hline & Hydroxymethylglutaryl-CoA synthase, cytoplasmic & 476 & $X P_{-} 801879.1$ & $56037 / 529$ & -1232 \\
\hline & Hypothetical protein (DAHP synthase family) & 753 & $\mathrm{XP}_{7} 783181.2$ & 3345815.84 & -2.913 \\
\hline & Hypothetical protein (DAHP synthasc family) & 757 & XP_783181.2 & $33458 / 5.84$ & -1.672 \\
\hline & Hypothetical protein (Proteasome alpha type 3) & 1054 & $\mathrm{XP}-796247.2$ & 2825315.61 & $\begin{array}{l}-1.072 \\
-1.607\end{array}$ \\
\hline & Intermediate Chain I & 59 & $\mathrm{XP}=786989.1$ & $89183 / 4.46$ & -1.816 \\
\hline & IMP cyclohydrolase & 360 & XP_793444.1 & $64315 / 6.13$ & $\begin{array}{l}-1.610 \\
-1264\end{array}$ \\
\hline & Isocilrate dehydrugenase $2(\mathrm{NADP}+)$, milochondrial & 695 & XP_001176537.1 & $50162 / 6.16$ & 1518 \\
\hline & Major yolk protein & 47 & SP 999740.1 & 153920704 & -1.822 \\
\hline & MGC143070 (Calponin domain) & 927 & XP 001191889.1 & $26196 / 4.89$ & -1.144 \\
\hline & Proleasome (prosorne, macropain) $26 \mathrm{~S}$ subunit, non-ATPase, 13 partial & 766 & $X P=001181294.1$ & $18475 / 4.95$ & -1.169 \\
\hline & Proteasome alpha 2 subunit & 1134 & XP_001199987.1 & $7330 / 9.01$ & -1.381 \\
\hline & PTK9I protein tyrosine kinase 9-like & 818 & XP_793525.1 & $34680 / 6.03$ & -1581 \\
\hline & Relinoblastoma binding prolein 4 variant isoform 2 & 397 & $\mathrm{XP}^{-}=801904.1$ & $49707 / 4.80$ & -1.145 \\
\hline & $\begin{array}{l}\text { RuvB-like } 2 \\
\text { (n) }\end{array}$ & 533 & XP 001184189 & $42412 / 5.62$ & -145 \\
\hline
\end{tabular}




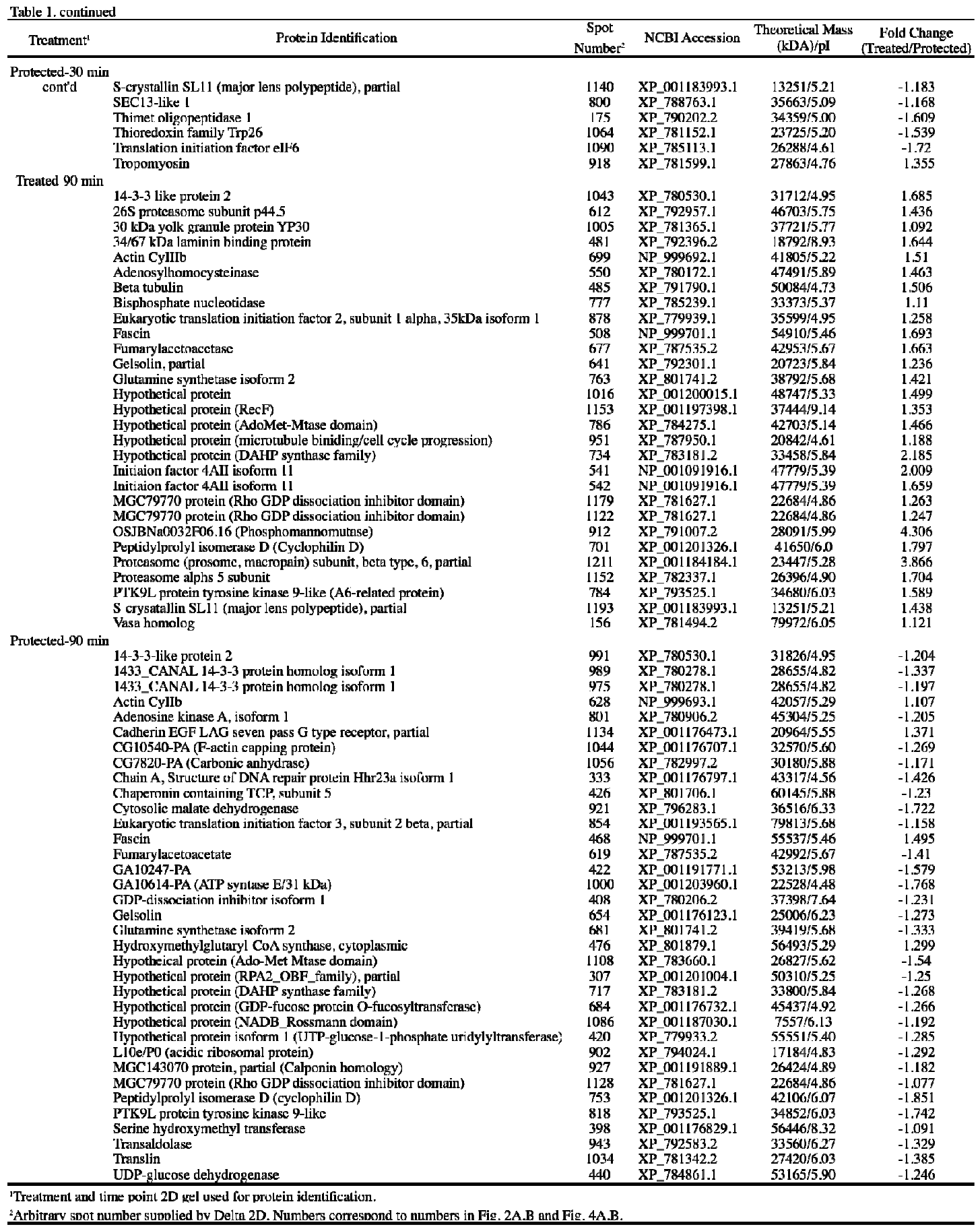


Interestingly, spots 753,786 and 1134 resulted in two separate identifications with significant MOWSE scores across the 30 and 90 min time points. For example at 30 min, spot 753 produced elevated spot expression in the UV-treated gels and was identified as Adenosine kinase A. At 90 min, spot 753 had elevated expression in UV-protected lysates of an identified hypothetical protein. Because the same spot at both times produced two different identifications, Adenosine kinase $\mathrm{A}$ at $30 \mathrm{~min}$ and a hypothetical protein at $90 \mathrm{~min}$, two different scenarios could be hypothesized. First, one or both of the identifications is incorrect, or second, the specific spot boundary set on the total proteome map represented two different protein spots, one at $30 \mathrm{~min}$ and one at $90 \mathrm{~min}$, and both were detected and positively identified as being differentially regulated by UVR. By detecting the same spot positions and numbers in the total fusion proteome map for $30 \mathrm{~min}$ and 90 min together, the protein spot boundaries representing different proteins at the two time points show that proteins moved into or out of a single spot boundary because of time and UVR. Therefore these protein identifications are justified as two different identifications, and represent different proteins that moved into or out of a single spot boundary set across 30 and 90 min due to UVR exposure.

Protein expression density clustering: Standardized expression volumes for all protein spots identified by mass spectrometry across all batches of embryos are represented in a map of expression density (Fig. 3). Both standardized protein spot expression density and embryo batch were hierarchically clustered in rows and columns respectively by a Pearson correlation. This figure shows the relative expression values of each identified protein spot across all gel images at each treatment level and compares expression density for each spot across all gels. The 
colors of each protein spot indicate the standardized expression of each spot, with blue representing higher values of standardized expression and orange representing lower values of standardized expression. Bootstrap analysis confirmed two main clusters of proteins, highlighted along the left of the map. These two clusters represent standardized expression of elevated and decreased protein spots by all batches of embryos for the same treatment. Protein identifications for each spot are listed along the right of each row.

Clustering the standardized expression of the identified proteins results in striking expression patterns between UV-treatments for each time point and indicates that specific proteins are either up or down regulated by UVR (Fig. 3). The perfect hierarchical clustering of samples by UV-treatment across the top of the figure demonstrates robust analysis of the identified proteins and implicates these proteins as being regulated by UVR. All proteins that show statistical differences in spot abundance between treatments and that were identified by MS show remarkable expression patterns between UV-treatments, producing two main clusters from the top to the bottom of the figure, those protein spots that have higher or lower expression values in either treatment. For example, the top row of the expression density map for 30 min post-fertilization indicates higher expression of a GTPbinding protein in all UV-protected batches, while the last row shows higher expression volumes of 14-3-3-like protein 2 in all UV-treated batches of embryos.

UV-treatment correlates strongly with protein spot expression levels (Fig. 3). Protein spots are either up or down regulated as indicated by the two clusters. The standardized expression values for all identified proteins across treatments were 
consistent in that a spot changing in expression density due to UVR had similar standardized values between batches and across UV-treatments. Only the two clusters of proteins were found among embryos exposed to UVR, indicating that all identified proteins have the same relative expression characteristics in response to UVR. Figure 3 shows sub-clustering of protein expression, but could not resolve any meaningful differences below the two main clusters.

Functional protein classifications: Functional classification of identified proteins was conducted initially using the NCBI Conserved Domain Database (CDD, Marchler-Bauer et al., 2009). This database search tool allowed for the identification of homologs and provided protein family information for a number of proteins. CDD analysis was followed with a survey of the current photobiological and developmental literature. All identified proteins fit broadly into seven general categories and showed varying trends in expression due to UV-treatment: (1) stress/repair; (2) protein translation; (3) cytoskeleton and cytoskeleton regulating proteins; (4) cellular metabolism; (5) signal transduction; (6) protein turnover and degradation; (7) other. Many of the identified proteins fit into a number of different categories. For example, HSP70, may have a dual role in mediating stress and protein turnover (Geraci and Sconzo, 2003). Proteins for which multiple functional categories could be found further enhanced their probable importance to monitoring and controlling cell cycle and embryonic development. Since the functional roles of proteins during development may be altered from that of later life history stages and/or during stress and since multiple proteins straddle multiple categories, these functional groups were not listed in table 1, but are discussed below. 


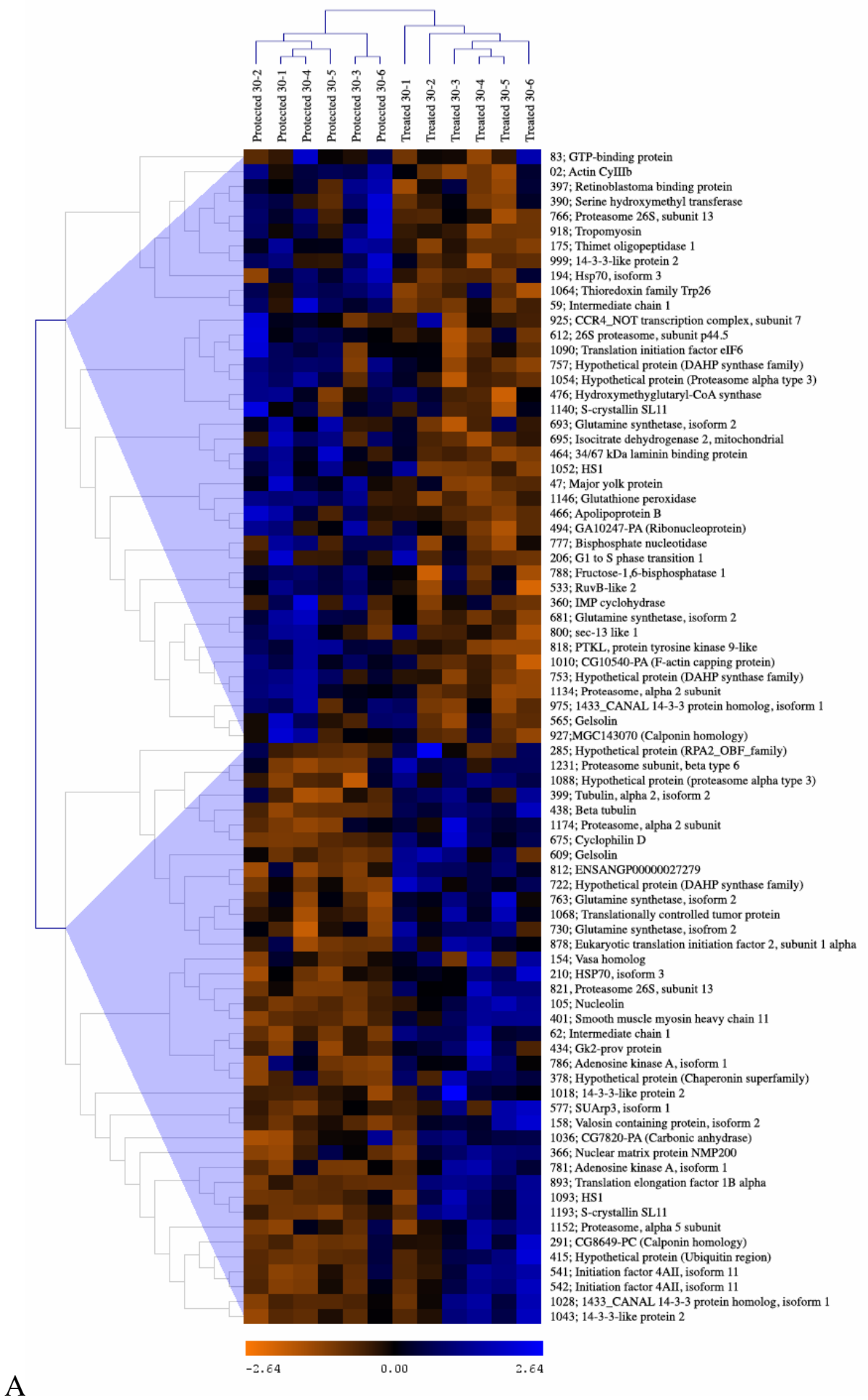




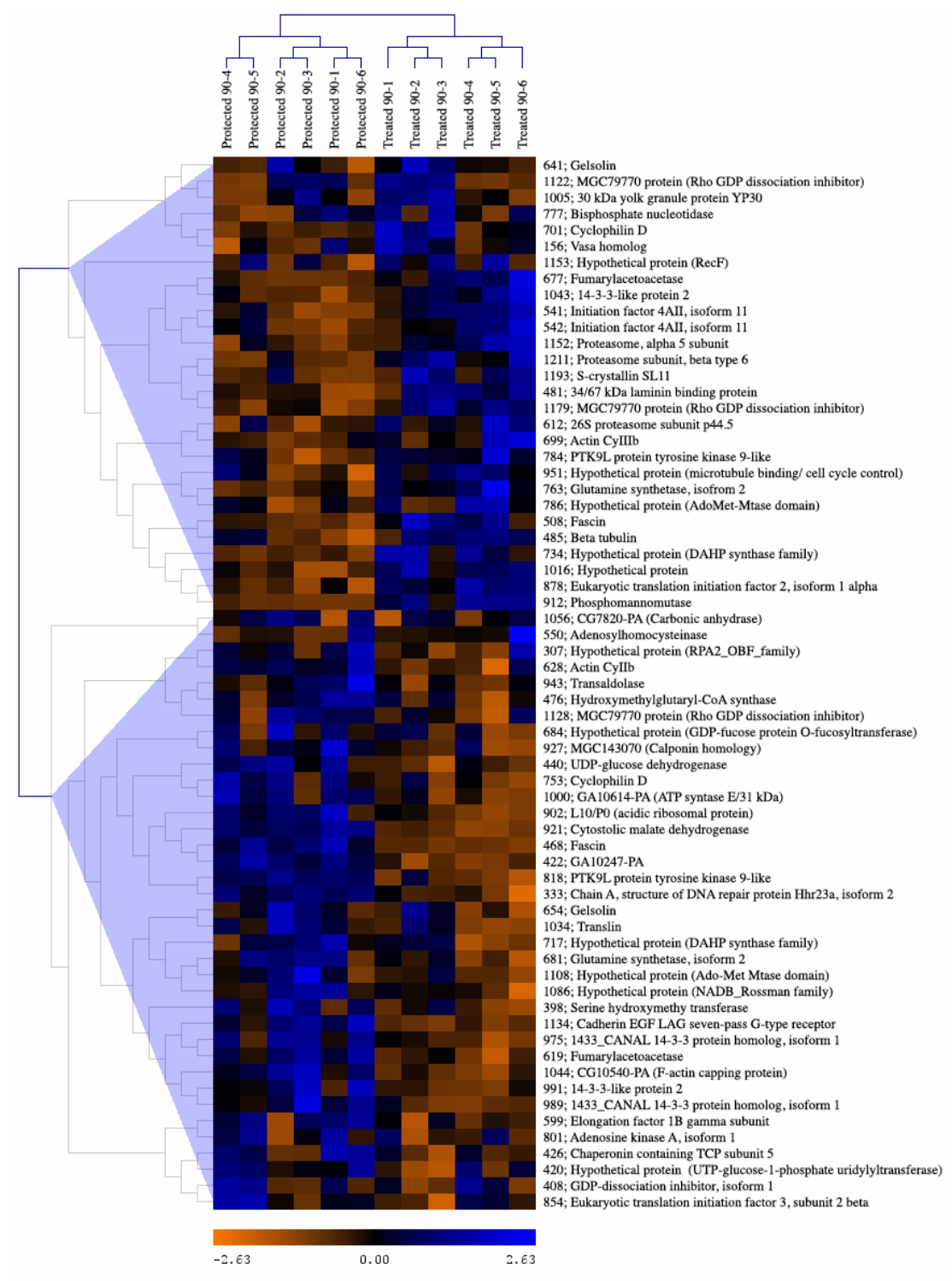

B

Fig. 3. Expression density map for MALDI-TOF MS identified proteins showing significant differentially regulated spot volumes (2-way ANOVA, factors of $S$. purpuratus embryo batch and UVR-treatment, $P<0.03$ based on 2000 permutations). (A) Expression density map for proteins identified within batches of embryos for all treatments at 30 min post-fertilization ( $n=6$ for the two UVtreatments), (B) batches of embryos for all treatments at 90 min post-fertilization. Expression density maps highlight two protein clusters showing significant spot expression differences due to UV-treatment on vertical axis. Protein clusters represents differentially expressed protein volumes according to their standardized expression density (note expression density color bar). Hierarchical clustering of each sample is noted on the top of each heat map (UV-protected and UV-treated, numbered by sea urchin embryo batch) using Pearson's Correlation. The spot number and identification is to the right of each row in the expression map. 


\section{Discussion}

Abiotic stressors, including UVR, $\mathrm{CO}_{2}$ and heavy metals cause developmental delays in sea urchin embryos (Fig. 1, Adams and Shick, 1996; Giese, 1964;

Kobayashi and Okamura, 2003; Kurihara and Shirayama, 2004). We sought to elucidate how expression/modification of the entire proteome is affected by environmentally relevant UVR during the early embryonic cell cycle. We examined effects of UVR on the sea urchin proteome at two specific cell cycle time points, 30 and 90 min post-fertilization (Fig.2). This study provides some of the first evidence demonstrating that multiple proteins and cellular pathways they are affected simultaneously by UV-irradiation or the mitotic delay it causes. Here, we present the most likely direct or indirect protein targets affected by UVR during the first mitotic phase of sea urchin development among embryos at $30 \mathrm{~min}$ and $90 \mathrm{~min}$ postfertilization (table 1).

Treating S. purpuratus embryos with ecologically relevant doses of UVR results in a delay of the first cell cycle post-fertilization (Fig. 1). We observed an average UV-induced developmental delay of nearly $20 \%$ between six UV-protected and UV-treated batches of embryos for the first cell cycle. This delay is consistent with delays observed in previous reports, but the protein targets and molecular mechanisms controlling this delay have not yet been elucidated (Adams and Shick, 1996; Giese 1964). S. purpuratus embryos vary in sensitivity to UVR across time during the first division (Adams et al., 2009 unpublished; Rustad, 1960), therefore we examined the proteomic differences between UV-protected and developmentally delayed UV-treated embryos at two time points representing distinct events during 
development. At 30 minutes post-fertilization, completion of the "sweep" of proteins transitioning the oocyte to an embryo has likely occurred (Stitzel and Seydoux, 2007) and major changes in the egg to embryo transition are over by 30 min (Roux et al, 2008). Also, DNA synthesis has been initiated in the male and female pronuclei in both UV-protected and UV-treated embryos (Rao and Hindgardner, 1965; Zeitz et al., 1968). At 90 minutes post-fertilization, the UV-protected embryos have commenced M-phase of mitosis and are starting to cleave while the UV-treated embryos have been shown to stall at the morphologically distinct streak stage in prophase (Rustad, 1971).

Proteomic assessment: Analysis of proteome profiles demonstrate that UVirradiation of embryos causes changes in proteins during the first cell cycle (Table 1, Fig. 2, 3). Figure 2 shows differences in spot expression patterns of UV-protected and UV-treated embryos at two time points during the embryonic cell cycle, and figure 3 shows the expression levels of each of these proteins across all batches at all treatments in a highly organized map of expression density. For each time point, UVtreatment led to two clear patterns of protein expression, spots being either up or down regulated. Hierarchical clustering of proteins from each treatment reveals that UVR (or the UV-induced delay) elevates expression of protein spots including Nucleolin, Vasa homolog protein, and Translation initiation factors including eIF4A, while simultaneously depresses expression of other protein spots including G1 to S phase transition protein, Isocitrate dehydrogenase and Transaldolase (Table1, Fig. 3).

The noticeable shifts in migration patterns of protein spots (identified within both treatments, Fig. 2) are most likely due to post-translational modifications rather 
than overall changes in translation because different spots sharing the same protein identification have two different spot boundary locations between the UV-treated and UV-protected batches of S. purpuratus embryos. Because proteins occupy two different spots between the two treatments (because they are not being turned over), they are a particularly interesting and important subset of proteins that we propose represent those that are part of the altered cellular signaling pathways controlling either the cell cycle or the developmental program during UVR stress. For example 14-3-3 protein spot expression was tracked between UV-treatments at both time points.

Identifying all possible PTMs of any individual protein spot caused by UVR is beyond the scope of the current experiments, but is planned for future investigation. Rather, these experiments were intended to provide an initial list of proteins that may be altered by UVR or the delays caused by UVR during early development. The proteins identified by MS + MS/MS and presented in table 1 are then a list of candidates for future studies to uncover the processes controlling differential expression patterns resulting after UVR-treatment.

The list of protein spots that differ between UVR treatments potentially represent proteins that mediate altered paths of cellular function. Because, we targeted proteins that focus in the $\mathrm{pH}$ 4-7 range, any protein with a $\mathrm{pI}$ outside of this range was not detected, limiting the power of substantiating any single pathway as the causative mechanism to understanding UVR induced delays in cleavage rates. Using similar methods to those described here, Roux et al. (2008) detected approximately 600 protein spots in sea urchin embryos between 0 to 30 min post-fertilization. We 
present an expanded detection of protein spots for later time points post-fertilization with a total of 1,306 detected protein spots.

We cannot reconcile whether proteins are directly or indirectly affected by UVR (proteins that are damaged by UVR directly or proteins that are responding to UVR induced macromolecular damage). Although specific PTM's were not identified because of the relative difficulty in both finding and then assessing each modification of the proteins presented in table 1 , each identification represents a potential marker of UVR stress regulated development. We speculate many of the observed shifts in spot positions along both the pI and MW axis are due to phosphorylation as seen in studies of Roux et al. (2006 and 2008) and backed with evidence in the literature of their potential phosphorylatable isoforms. Our future studies will focus more on identifying the causes of these shifts.

Similarly, this study does not attempt to identify whether differences are due to the direct photochemical damage of proteins or the delays caused by UVRtreatment. We cannot distinguish between these two processes, but the expression density maps (Fig. 3) show that a large subset of proteins in the UV-treated cells have higher expression values compared to the UV-protected cells. These include cytoskeletal proteins such as Tubulin and Actin CyIIb; many proteins making up the proteasome and involved in protein turnover including the $26 \mathrm{~S}$ and p44.5 subunits; proteins involved in subcellular trafficking including HSP70 and Cyclophilin D; and many others. Therefore we assert that both differential regulation of proteins via PTM or translation are the major sources of elevated spot expression volume over that of UVR causing general protein turnover. 
The bootstrap analysis did not resolve any sub-clustering below the two main clusters with any certainty, therefore, the figure represents only hypothetic subclusters of proteins, which may indicate these proteins are regulated by a particular cellular pathway. Future studies may provide a more sensitive analysis of the expression characteristics for proteins mediating UVA versus UVB stress by performing a similar experiment using light filters to produce both of these treatments.

The molecular basis of stressed-induced cell cycle delays has been studied in many other organisms. For example, Kültz, (2005) details the CSR by itemizing the minimal cellular stress response proteome. Several proteins identified in our proteomic analysis are consistent with those described in Kültz (2005) including 143-3 protein, HSP70, Cyclophilin D, Glutathione peroxidase, 26S proteasome, Isocitrate dehydrogenase, Thioredoxin and the nucleotide excision repair protein $\operatorname{Rad} 23$ (Hhr23). The remainder of this discussion will focus on the proteins possibly mediating cell cycle delay and their participation in this cellular stress response. We will also attempt to classify these proteins based on the functional categories found by the CDD analysis and supported by literature.

\section{Proteins potentially involved in UVR induced mitotic delay:}

Signal transduction: We have identified 14-3-3 protein and a number of 14-3-3

homologs (including HS1) from all treatments at every time point as being differentially regulated. In particular, each of these proteins was found to be shifted to a slightly lower molecular weight in UV-treatments from that over the UV-protected treatments (Figure 2). This minor deviation in molecular weight could be a result of 
PTM, including a change in phosphorylation state at a number of phosphorylatable residues. 14-3-3 proteins regulate signaling transduction pathways including cell cycle control and apoptosis (Ferl et al., 2002; Fu et al., 2000). Of particular note is its involvement in the regulation of $\mathrm{Cdc} 25$, a phosphatase required for the dephosphorylation and activation of $\mathrm{Cdc} 2$, a subunit of the mitosis promoting factor complex (MPF, Cdc2/ cyclin B, Borgne and Meijer, 1996). Gabrielli et al. (1997) characterized the Cdc25-dependent retarded activation of MPF in UVC-irradiated HeLa cells delayed in the G2 to M phase of the cell cycle. In addition, Moreau et al. (1998) showed that in the presence of the Cdc2 inhibitor, p21, DNA synthesis is not delayed, further indicating that regulation cell cycle controls (Cdc25 and Cdc2) are independent of S-phase of the cell cycle and could partially explain the delay in UVinduced cleavage delays.

More importantly, UV-irradiation results in p38 dependent phosphorylation of Cdc25, which initiates binding to $14-3-3$ protein and is a critical step in halting the cell cycle as a result of a DNA damage checkpoint in mammalian cells (Bulavin et al., 2001). If DNA damage checkpoints at the G2/M transition are acting upstream of 14-3-3, the delayed activation of $\mathrm{Cdc} 25$ and further Cdc2 of MPF would then explain, in part, the cell cycle delay of the UVR induced delays in the embryonic cell cycle. More recently, Adams et al. (2009 in preparation) has shown that UV-irradiation of sea urchin embryos does not affect the concentration of Cyclin B, but causes the delayed removal of the inhibitory Tyrosine 15 phosphorylation from Cdc2, delaying MPF activation. This delay in phosphorylation may be due to inhibition of Cdc25 upstream by Chk1 activated 14-3-3 protein. 
Recently, the sea urchin genome sequence was published and has led to insights about the number and types of DNA damage checkpoint kinases available to the sea urchin (Fernandez-Guerra et al., 2006; Sodergren et al, 2006). Sea urchins have DNA damage Chk1 kinase (NCBI Accession: NP_001091925) and it is expressed in the eggs and early embryos of the purple sea urchin (G. Goschke, M.S. thesis). This means sea urchin embryos may be primed to sense UV-induced DNA damage. Human keratinocytes exposed to UVR experience cell cycle arrest that is correlated to concentrations of both Chk1 (a Cdc25 inhibitory kinase) and Cdc25 (Athar et al., 2000). Although Cdc2, Cyclin B, Chk1 or Cdc25 were not identified in this study, likely because some have pIs outside of the 4-7 $\mathrm{pH}$ range or may not be soluble in TritonX-100 lysis buffer, we may be able to infer that our identification of the changes in14-3-3 described above indicate that these proteins could be affected. We are currently focusing efforts to expand our range of detection to examine how UVR affects proteins in the $\mathrm{pH} 7-10$ range.

More specifically, a subset of the total 14-3-3 protein in S. purpuratus embryos occupies different spot locations on all UV-treated gels than on all UVprotected gels (e.g. spot 1028 and 975 or spot 1018 and 999 respectively, Fig. 2), and this differential regulation of spot expression may be a result of PTM, which then can modify its relationship with Cdc25. If this is occurring, the differential regulation of 14-3-3 protein could partially explain the UVR induced cell cycle delay. Further it would link observations of CPD formation and the relative increases of Cdc2 inhibitor protein p21 in UV-irradiated sea urchin embryos (Lesser et al., 2003) and also confirm the delayed activation of Cdc2 seen by Adams and Foltz (2002). 
Stress and repair proteins: We identified multiple HSP70 and Cyclophilin D protein spots. These proteins are important for their role as molecular chaperones in both the cytosol and the mitochondria of eukaryotic cells, and appear to play roles in the CSR (Kültz, 2005). Our data indicate that UV-irradiation of embryos causes the pI of HSP70 to become more acidic compared to protected embryos at 30 min postfertilization, possibly due to PTM (spot 210 and 194 respectively, Fig. 2A). This difference could indicate a change in function of HSP70, which is known to interact with both cell cycle proteins and the cytoskeleton. There were no differences in expression for HSP70 at 90 min post-fertilization.

HSP70 has been well studied in the sea urchin Paracentrotus lividus for which four isoforms have been characterized (Sconzo et al., 1997). Importantly, HSP70 localizes on the mitotic asters with Cdc2/ Cyclin B in dividing sea urchin oocytes (Geraci et al., 2003) and further is required for proper assembly of the mitotic asters during cell division (Sconzo et al., 1999). Agueli et al., (2001) proposed the importance of HSP70 in performing an essential chaperone role for tubulin folding during the assembly of the sea urchin cleavage embryo mitotic apparatus. HSPs also may regulate key cell cycle proteins, highlighting their importance in the cell cycle (Geraci et al., 2003; Helmbrecht et al., 2000). Moreover, UV-irradiation of early cleavage stage sea urchin embryos stimulates HSP70 expression (Bonaventura et al., 2006) and this expression is an important indicator of UVR stress early in development (Bonaventura et al., 2005). These studies indicate that early cleavage sea urchin embryos are sensitive to UV-stress, which has the ability to alter developmental phenotypes in later stage embryos as a result. HSP70 activity is also sensitive to intracellular $\mathrm{Ca}^{2+}$ concentrations (Kiang and Tsokos, 1998). Calcium flux 
at fertilization is known to be playing an essential role in egg activation and the resumption of the mitotic cell cycle (Whitaker, 2006). Taken together, HSP70 is essential to the cell cycle and also sea urchin development, plays an important chaperone role in protein folding, and may be a part of refolding UV-damaged proteins.

We have also identified the differential migration of Cyclophilin D by detecting shifts in molecular weight among the 90 min treatments and also shifts in MW and pI between 30 and 90 min (spots 675, 701 and 753 respectively, Fig. 2). Cyclophilin D is an important mitochondrial chaperone that protects cells against apoptosis (Lin and Lechleiter, 2002). Cyclophilin D plays an important role in regulating the mitochondrial permeability transition pore complex, essential to detecting the redox state of the mitochondria and recognizing intracellular $\mathrm{Ca}^{2+}$ flux (Green and Reed, 1998). Furthermore, the permeability transition pore complex as the mastermind of mitochondrial regulated apoptotic pathways (Green and Reed, 1998). Overexpression of Cyclophilin D in mouse heart cells leads to enhanced cell death, further indicating Cyclophilin D may have an essential role in controlling mitochondrial permeability during calcium flux and oxidative stress (Baines et al., 2004). Therefore we hypothesize that Cyclophilin D may be controlling the sensing of cellular redox states and UV-induced changes within these embryos, which are already heightened because of the respiratory burst after fertilization (Shapiro, 1991).

Shortly after fertilization, a respiratory burst transitions the metabolically quiescent egg to a rapidly dividing embryo results in the production of ROS (Shapiro, 1991; Wong et al., 2004). As part of the CSR, an oxidative burst is also known to 
occur within stressed cells (Kültz, 2005). We document UV-induced changes in a large number of proteins that are hallmarks of oxidative stress. For example, Glutathione peroxidases and Thioredoxin exhibit nearly 4 or 1.5 fold increases in UV-treated embryos respectively, S-crystallin protein shifts in MW between the 30 min UV treatments, and Carbonic anhydrase had a 1.5 fold increase at 30 min and a 1.17 fold decrease at 90 min in UV-treated embryos (Table1, Fig. 2, and Fig. 3). The sequencing of the $S$. purpuratus genome allowed a very detailed analysis of the sea urchin chemical defensome (Goldstone et al., 2006), which described both the number and the expression patterns of oxidative defense genes, including Glutathione peroxidase and Thioredoxin expressed in sea urchin embryos.

Proteins that have roles in protecting cells against oxidative stress could be regulated differently as a result of UV-irradiation or developmental delay. These proteins may have dual functions, acting as the regulators of ROS from the oxidative burst naturally occurring after fertilization and also may be compounded by the UVinduced production of ROS during UVR exposures starting within 3 min after fertilization. These two processes independently are stressful to cells and synergistically may be even more stressful to embryos when both are acting concurrently. We show that there are differences in oxidative stress protein spots between UVR treated embryos between 30 and 90 min post-fertilization and this difference could also be contributing to the delay seen between UV-treatments.

Protein degradation: Numerous subunits of the major protein-degrading complex, the proteasome, were differentially regulated between UV-treatments and time points (e.g.s alpha 2, alpha 3, alpha 5, beta 6 and regulatory 26S subunit) (Fig. 2, Table 1). 
At 30 min post-fertilization UV-treated embryos exhibited a nearly 1.8 fold decrease of the $26 \mathrm{~S}$ proteasome non-ATPase subunit. The p44.5 subunit increased 1.3 fold at $30 \mathrm{~min}$ and 1.4 fold at $90 \mathrm{~min}$ in the UV-treated embryos. Proteasome alpha 2 subunit shifted to a higher MW in UV-treated embryos at 30 min post-fertilization compared to UV-protected embryos (spot 1134 and 1174 respectively). All other subunits display differential migration between UV-treatments, which may demonstrate they also have roles involved in the differential regulation of protein turnover in UVstressed embryos. Furthermore, the identification of a large number of proteasome subunits highlights the probable importance of the entire proteasome complex in regulating transitional phases of the cell cycle and a response to UV-induced damage.

Although there is a distinct increase in proteasome activity during egg activation and the egg to embryo transition (Horner and Wolfner, 2008), there is some indication of a chaperone role for the 26S subunit in stabilizing nucleotide excision repair (NER) with Hhr23 (Glockzin et al., 2003). Verma et al. (2000) has characterized three classes of proteasome interacting proteins including HSP70, which may further elevate the importance of HSP70 as a mediator of UV-induced delay.

As a result of UV-stress (Kültz, 2005) the proteasome complex may also mediate the polyubiquination and subsequent degradation of p53 in humans (Glockzin et al., 2003). Furthermore, p53 has also been identified in sea urchin embryos and may play a role in the apoptotic pathway activated after UV-stress later in development (Lesser et al., 2003). Additionally, inhibition of the proteasome blocks mitosis in sea urchin embryos by delaying the activation of MPF 
(dephosphorylation of $\mathrm{Cdc} 2$ ) and further regulates exit from S-phase of the cell cycle (Kawahara et al., 2000), highlighting the importance of degrading proteins throughout the cell cycle. It may also be important to degrade proteins that have activated the CSR in order to stop any further UVR-induced developmental delay.

Cytoskeleton and cytoskeleton regulating proteins: We expected to identify differentially regulated proteins for cytoskeleton and cytoskeleton regulation. There is no question that UV-induced delays in cell division are linked to the timing of the proteins controlling the physical aspects of pronuclear localization, chromosomal segregation, cleavage furrow formation and the actual separation of the two daughter cells. Very little attention has been given to the effect of UVR on cytoskeletal elements, but importantly, UVR disrupts cytoplasmic microtubules in human skin cells (Zamansky and Chou, 1987) and affects microtubule stability while having limited structural effects on microfilaments in somatic cells (Veselká and Janisch, 2000).

We have identified differential migration of numerous cytoskeletal proteins including Actins and Tubulins for all time points and UV-treatments (Table 1). Presumably the regulation is a PTM resulting in differences in cytoskeletal assembly because we do not typically see differences in the total amount of these proteins due to UVR (personal observation using western blotting). Also, we believe the regulation of these proteins is a part of the UV-induced cell cycle delay because we tracked Gelsolin (Fig. 2, Table 1, Fig. 3), a regulator of Actin polymerization/severing (Sun et al., 1999), in all treatments and all time points. The change in migration of Gelsolin is particularly interesting because it indicates that 
UV-treated embryos may be physically stalled in the cell cycle because of altered regulation and function of the actin cytoskeleton. We further document a 1.4 fold increase of a protein spot identified as SUArp3, an actin-related protein, and a UVmediated 1.3 fold decrease in F-actin capping protein in UV-treated embryos at both 30 and $90 \mathrm{~min}$. These results indicate that regulation of the cytoskeleton is altered after UV-treatment and may be associated with the delay at prophase characteristic of UV-induced cell cycle delays in sea urchin embryos (Rustad, 1971).

Additionally, we were able to track multiple protein spots identified as RhoGDP dissociation inhibitor at both of the 90 min treatments (Table 1, spots 1122, 1128 and 1179 in Fig. 2A, Fig. 3A). Rho-GTPases appear to play a role in cytokinesis by promoting the growth of mictotubules especially during interphase of the cell cycle (Robinson and Spudich, 2000). Our identification of the differential migration of Rho family inhibiting proteins in both treatments at 90 min may lead to further coordinated signaling within these cells to re-coordinate or prevent assembly of the cytoskeleton during developmental delay. We saw shifts in MW and pI for Rho GDP dissociation inhibiting proteins at 90 min post-fertilization. Spot 1128 was identified from the UV-protected lysates and shifts in UV-treated lysates are toward a lower MW for spot 1179 and toward a higher MW and more acidic pI for spot 1122. Lastly, Robinson and Spudich (2000) highlight the role of active MPF in regulating the cytoskeletal elements, which would make the identifications of HSP70 and 14-3-3, discussed above, as important regulators of the cytoskeleton through the action of MPF. 
Cellular metabolism: We identified a potentially important metabolic enzyme that also has a role in mediating oxidative stress in cells. Mitochondrial Isocitrate dehydrogenase $2(\mathrm{NADP}+)$ was down regulated in UV-treated embryos by 1.5 fold at 30 min (Fig. 2, Table 1, Fig. 3). This identification is important because mitochondrial Isocitrate dehydrogenase plays a role in recycling NADP+ within the mitochondria and overexpression results in protection from ROS induced damage in mouse NIH3T3 cells (Jo et al., 2001). This indicates that sea urchin embryos may have an altered capacity to sense and cope with ROS. Moreover, the activity of Isocitrate dehydrogenase is regulated by glutationylation during periods of oxidative stress (Kil and Park, 2005). Our results, in addition to previously published literature, may indicate the relative importance in regulating the activity of this enzyme, especially during UV-induced oxidative stress conditions. If UV-stressed sea urchin embryos carry a decreased ability to regulate redox flux within the mitochondria or use a different strategy to regulate ROS using ovothiols, the accumulation of damage from ROS could be contributing to macromolecular damage and activation of the CSR.

Protein translation: Iordanov et al. (1998) has asserted that part of the cellular response to UV-stress may be generated at the ribosome from damaged rRNA. We were able to identify L10e/P0 (an acidic ribosomal protein) as changing nearly 1.3 fold in UV-treated cells. Further, in all UV-treated lysates, we have identified increases in proteins spots for eIF2 and eIF4AII, proteins required for the initiation of translation. eIF2 kinases have been shown to play a role in UV-induced apoptosis in human cells, in part due to the phosphorylation of eIF2 (Parker et al., 2006). Last, we identified a two-fold increase in Nucleolin in the UV-treated lysates. 
Overexpression of Nucleolin inhibits the translation of p53 and Nucleolin down regulation promotes the expression of p53 along with ribosomal subunits in mammals after DNA damage (Takagi et al., 2005). Although we cannot state that the protein spot we identified is the active or inactive form of Nucleolin, it may have a role in stalling the cell cycle by controlling the levels of p53 during and after UV-exposure that may not necessarily have a direct effect on controlling delays in division (Pavey et al., 2001).

Conclusions: We provide the most comprehensive study documenting the proteome responses in the sea urchin early cleavage embryo to UV-stress using 2D GE and MALDI-TOF-TOF MS. The list of proteins identified here are representatives from a number of different cellular pathways affected by UVR and will serve as future potential targets. Most notably we have identified cellular targets from numerous pathways including cell cycle regulation through signal transduction proteins, protein turnover and stress mediation simultaneously. Additional functional data from a subset of the proteins identified here may help resolve the longstanding question regarding the mechanism by which UV-stress alters cellular physiology resulting in delays and subsequent abnormalities in development. Also, we suspect the detection of specific PTMs made to many of the proteins we have identified will become essential to understanding both regulation and activity during UV-induced stress. Identifying these pathways and proteins will lead to a better identification of mechanisms involved in UV-stress at the physiological level. Assessing UV-stress in from a global proteomic viewpoint will elucidate the impact future UV-fluctuations will have on marine invertebrate embryos specifically and cells in general. We present a list of proteins that may be used as potential biomarkers or proteins involved 
in novel pathways to alleviate UV-stress in marine organisms. 


\section{Literature Cited}

Adams, N. and Shick, J. M. (1996). Mycosporine-like amino acids provide protection against ultraviolet radiation in eggs of the green sea urchin Strongylocentrotus droebachiensis. Photochem. Photobiol. 64, 149-158.

Adams, N. and Shick, J. M. (2001). Mycosporine-like amino acids prevent UVBinduced abnormalities during early development of the green sea urchin Strongylocentrotus droebachiensis. Mar. Biol. 138, 267-280.

Adams, N., Shick, J. M., Dunlap, W. (2001). Selective accumulation of mycosporine-like amino acids in ovaries of green sea urchin, Strongylocentrotus droebachiensis, is not affected by ultraviolet radiation. Mar. Biol. 138, 284-294.

Adams, N. L. and Foltz, K. R. (2002). A molecular approach to understanding UVinduced mitotic delay in sea urchin embryos. Proceedings from the North American Echinoderm Conference 2001 Gulf of Mexico Sciences, 19 (2), 165. (Abstract)

Agueli, C., Geraci, F., Giudice, G., Chimenti, L., Cascino, D., Sconzo, G. (2001). A constitutive $70 \mathrm{kDa}$ heat-shock protein is localized on the fibres of spindles and asters at metaphase in an ATP-dependent manner: a new chaperone role is proposed. Biochem. J. 360, 413-419.

Akimoto, Y. and Shiroya, T. (1987). Photoreversal of abnormal morphogenesis in sea-urchin embryos cause by UV-irradiation. Photochem. Photobiol. 45, 403406.

Anderson, S., Haffman, J., Wild, G., Basch, I., Karentz, D. (1993). Cytogenetic, cellular, and developmental responses in Antartic sea urchins (Sterechinus neumayeri) following laboratory ultraviolet-B and ambient solar radiation exposures. Antarct J. 28, 115-116.

Anderson, S., Zepp, R., Machula, J., Santavy, D., Hansen, L., Mueller, E. (2001). Indicators of UV exposure in corals and their relevance to global climate change and coral bleaching. Hum. Ecol. Risk Assess. 7, 1271-1282.

Athar, M. Kim, A. L., Ahmad, N., Mukhtar, H., Gautier, J., Bickers, D. R. (2000). Mechanism of ultraviolet B-induced cell cycle arrest in G2/M phase in immortalized skin keratinocytes with defective p53. Biochem. Bioph. Res. Co. 277, 107-111. 
Baines, C. P., Kaiser, R. A., Purcell, N. H., Blair, N. S., Osinska, H., Hambleton, M. A., Brunskill, E. W., Sayen, M. R., Gottlieb, R. A., Dorn, G. W., Robbins, J., Molkentin, J. D. (2004). Loss of cyclophilin D reveals a critical role for mitochondrial permeability transition in cell death. Nature. 434, 658662.

Bancroft, B. A., Baker, N. J., Blaustein, A. R. (2007). Effects of UVB on marine and freshwater organisms: a synthesis through meta-analysis. Ecol. Lett. 10, 332-345.

Berth, M., Moser, F. M., Kolbe, M., Bernhardt, J. (2007). The state of the art in the analysis of two dimensional gel electrophoresis images. Appl. Microbiol. Biotechnol. 76, 1223-1243.

Borgne, A. and Meijer, L. (1996). Sequential dephosphorylation of p34 ${ }^{\mathrm{cdc} 2}$ on Thr-14 and Tyr-15 at the prophase/metaphase transition. J. Biol. Chem. 271, 2784727854.

Bonaventura, R., Poma, V., Costa, C., Matranga, V. (2005). UVB radiation prevents skeleton growth and stimulates expression of stress markers in sea urchin embryos. Biochem. Bioph. Res. Co. 328, 150-157.

Bonaventura, R., Poma, V., Russo, R., Zito, F., Matranga, V. (2006). Effects of $\mathrm{UV}-\mathrm{B}$ radiation on development and hsp70 expression in sea urchin cleavage embryos. Mar. Biol. 149, 79-86.

Bosch, I., Beauchamp, K., Steele, E., Pearse, J. (1987). Development, metamorphosis, and seasonal abundance of embryos and larvae of the Antarctic sea urchin Sterechinus neumayeri. Biol. Bull. 173, 126-135.

Bradham, C.A., Foltz, K.R., Beane, W.S., Arnone, M.I., Rizzo, F., Coffman, J.A., Mushegan, A., Goel, M., Morales, J., Geneviere A., Laparz F., Robertson, A.J., Kelkar, H., Loza-Coll, M., Townley, I.K., Raish, M., Roux, M.M., Lepage, T., Gache, C., McClay D.R., Manning, G. (2006). The sea urchin kinome: a first look. Dev. Biol. 300, 180-193.

Bulavin, D. V., Higashimoto, Y., Popoff, I. J., Gaarde, W. A., Basrur, V., Potapova, O., Appella, E., Fornace, A. J. (2001). Initiation of a G2/M checkpoint after ultraviolet radiation requires p38 kinase. Nature. 411, 102107.

Caldwell, M. M., Björn, L. O., Bornman, J. F., Kulandiavelu, G., Teramura, A. H., Tevini, M. (1998). Effects of increased solar ultraviolet radiation on terrestrial ecosystems. J. Photoch. Photobio. B. 46, 40-52. 
Carroll, A. K. and Shick, J. M. (1996). Dietary accumulation of UV-absorbing mycosporine-like amino acids (MAAs) by the green sea urchin (Strongylocentrotus droebachiensis). Mar. Biol. 124, 561-569.

Cullen, J. and Neale, P. (1994). Ultraviolet radiation, ozone depletion, and marine photosynthesis. Photosynth. Res. 39, 303-320.

Day, T. A. and Neale, P. J. (2002). Effects of UV-B radiation on terrestrial and aquatic primary producers. Annu. Rev. Ecol. Syst. 33, 371-396.

Denney, M. and Shibata, M. (1989). Consequences of surf-zone turbulence for settlement and external fertilization. Am. Nat. 134, 859-889.

Dunlap, W. C. and Shick, J. M. (1998). Ultraviolet radiation-absorbing mysosporine-like amino acids in coral reef organisms: a biochemical and environmental perspective. J. Phycol. 34, 418-430.

Epel, D. (2003). Protection of DNA during early development: adaptations and evolutionary consequences. Evol. Dev. 5, 83-88.

Ferl, R. J., Manak, M. S., Reyes, M. F. (2002). The 14-3-3s. Genome Biol. 3, 3010.1-3010.7.

Fernandez-Guerra, A., Aze, A., Morales, J., Mulner-Lorillon, O., Cosson, B., Cormier, P., Bradham, C., Adams, N. L., Robertson, A. J., Marzluff, W. F., Coffman, J. A., Genevière, A. M. (2006). The genomic repertoire for cell cycle control and DNA metabolism in S. purpuratus. Dev. Biol. 300, 238251.

Fu, H., Subramanian, R. R., Masters, S. C. (2000). 14-3-3 Proteins: structure, function, and regulation. Annu. Rev. Pharmacol. 40, 617-647.

Gabrielli, B. G., Clark, J. M., McCormack, A. K., Ellem, K. A. O. (1997). Ultraviolet light-induced G2 phase cell cycle checkpoint blocks cdc25dependent progression into mitosis. Oncogene. 15, 749-758.

Geraci, F. and Sconzo, G. (2003) Constitutive HSP70 role in sea urchin embryos during mitosis. Recent Res. Devel. Biophys. Biochem. 3, 327-332.

Geraci, F., Agueli, C., Giudice, G., Sconzo, G. (2003). Localization of HSP70, $\mathrm{Cdc} 2$, and cyclin B in sea urchin oocytes in non-stressed conditions. Biochem. Bioph. Res. Co. 310, 748-753.

Giese, A. (1938). The effects of ultra-violet radiation of 2537A upon cleavage of sea urchin eggs. Biol. Bull. 74, 330-341. 
Giese, A. (1946). Comparative sensitivity of sperm and eggs to ultraviolet radiations. Biol. Bull. 91, 81-87.

Giese, A. (1964). Studies on ultraviolet radiation action upon animal cells. In: Photophysiology, vol II (ed. Giese, A.), pp 203-245. New York: Academic.

Glockzin, S., Ogi, F. X., Hengstermann, A., Scheffner, M., Blattner, C. (2003). Involvment of the DNA repair protein hHR23 in p53 degradation. Mol. Cell Biol. 23, 8960-8969.

Goel, M. and Mushegian, A. (2006). Intermediary metabolism in sea urchin: the first inferences from the genome sequence. Dev. Biol. 300, 282-292.

Goldstone, J. V., Hamdoun, A., Cole, B. J., Howard-Ashby, M., Nebert, D. W., Scally, M., Dean, M., Epel, D., Hahn, M. E., Stegean, J. J. (2006) The chemical defensome: environmental sensing and response genes in the Strongylocentrotus purpuratus genome. Dev. Biol. 300, 366-384.

Goschke, G. A. (2005). The presence and activity of Chk1 in the UV-induced cellular response in the purple sea urchin, Strongylocentrotus purpuratus. M.S. Thesis, California Polytechnic State University, San Luis Obispo.

Green, D. R. and Reed, J. C. (1998). Mitochondria and Apoptosis. Science. 281, 1309-1312.

Häder, D., Kumar, H., Smith, R., Worrest, R. (1998). Effects on aquatic ecosystems. In: Environmental effects of ozone depletion: 1998 assessment (ed. van der Leun, J., Tang, X., Tevini, M.), pp 53-68. New York: Environment programme report, United Nations.

Häder, D. and Sinha, R. P. (2005). Solar ultraviolet radiation-induced DNA damage in aquatic organisms: potential environmental impact. Mut. Res. 571, 221-233.

Häder, D., Kumar, H., Smith, R., Worrest, R. (2007). Effects of solar UV radiation on aquatic ecosystems and interactions with climate change. Photochem. Photobiol. Sci. 6, 267-285.

Hamdoun, A. and Epel, D. (2007). Embryo stability and vulnerability in an always changing world. P. Natl. Acad. Sci. 104, 1745-1750.

Hamer, B., Pavi i Hamer, D., Müller, W.E.G., Batel, R. (2004). Stress-70 proteins in marine mussel Mytilus galloprovincialis as biomarkers of environmental pollution: a field study. Environ. Int. 30, 873-882. 
Helmbrecht, K., Zeise, E., Rensing, L. (2000). Chaperones in cell cycle regulation and mitogenic signal transduction: a review. Cell Prolif. 33, 341-365.

Helmuth, B., Harley, C. D. G., Halpin, P. M., O'Donnell, M., Hofmann, G. E., Blanchette, C. A. (2002). Climate change and latitudinal patterns of intertidal thermal stress. Science. 298, 1015-1017.

Hoffman, J. R., Hansen, L. J., Klinger, T. (2003). Interactions between UV radiation and temperature limit inferences from single-factor experiments. $J$. Phycol. 39, 268-272.

Hofmann, G. E., Burnaford, J. L., Fielman, K, T. (2005). Genomics-fueled approaches to current challenges in marine ecology. Trends Ecol. Evol. 20, 305-311.

Hollósy, F. (2002). Effects of ultraviolet radiation on plant cells. Micron. 33, 179197.

Horner, V. L. and Wolfner, M. F. (2008). Transitioning from egg to embryo: triggers and mechanisms of egg activation. Dev. Dyn. 237, 527-544.

Howard-Ashby, M., Materna, S. C., Brown, T., Tu, Q., Oliveri, P., Cameron, R. A., Davidson, E. H. (2006). High regulatory gene use in sea urchin embryogenesis: implications for bliaterian development and evolution. Dev. Biol. 300, 27-34.

Hunt, T., Luca, F., Ruderman, J. (1992). The requirements for protein synthesis and degradation, and the control of destruction of cyclins A and B in the meiotic and mitotic cell cycles of the clam embryo. J. Cell Biol. 116, 707-724.

Imlay, J. and Linn, S. (1988). DNA damage and oxygen radical toxicity. Science. 240, 1302-1309.

Iordanov, M. S., Pribnow, D., Magun, J. L., Dinh, T. H., Pearson, J. A., Magun, B. E. (1998) Ultraviolet radiation triggers the ribotoxic stress response in mammalian cells. J. Biol. Chem. 273, 15794-15803.

Jo, S. H., Son, M. K., Koh, H. J., Lee, S. M., Song, I. H., Kim, Y. O., Lee, Y. S., Jeong, K. S., Kim, W. B., Park, J. W., Song, B. J., Huhe, T. L. (2001). Control of mitochondrial redox balance and cellular defense against oxidative damage by mitochondrial NADP+-dependent isocitrate dehydrogenase. $J$. Biol. Chem. 276, 16168-16176. 
Karentz, D. and Lutze, L. (1990). Evaluation of biologically harmful ultraviolet radiation in Antarctica with biological dosimeter designed for aquatic environments. Limnol. Oceanogr. 35, 549-561.

Karl, T. R. and Trenberth, K. E. (2003). Modern global climate change. Science. 302, 1719-1723.

Kawahara, H., Phillipova, R., Yokosawa, H., Patel, R., Tanaka, K., Whitaker, M. (2000). Inhibiting proteasome activity causes overreplication of DNA and blocks entry into mitosis in sea urchin embryos. J Cell Sci. 113, 2659-2670.

Kerr, J. and McElroy, C. (1993). Evidence for large upward trends of ultraviolet radiation linked to ozone depletion. Science. 262, 1032-1034.

Kiang, J. G. and Tsokos, G. C. (1998). Heat shock protein $70 \mathrm{kDa}$ molecular biology, biochemistry, and physiology. Parmacol. Ther. 80, 183-201.

Kil, I. S. and Park, J. W. (2005). Regulation of mitochondrial NADP+-dependent isocitrate dehydrogenase activity by glutathionylation. J. Biol. Chem. 280, 10846-10854.

Kobayashi, N. and Okamura, H. (2003). Effects of heavy metals on sea urchin embryo development. 1. Tracing the cause and effects. Chemosphere. 55, 1403-1412.

Kultz, D. (2005). Molecular and evolutionary basis of the cellular stress response. Annu. Rev. Physiol. 67, 225-257.

Kurihara, H. and Shirayama, Y. (2004). Effects of increased atmospheric $\mathrm{CO}_{2}$ on sea urchin early development. Mar. Ecol. Prog. Ser. 274, 161-169.

Lesser, M. P., Stochaj, W. R., Tapley, D. W., Shick, J. M. (1990). Bleaching in coral reef anthozoans: effects of irradiance, ultraviolet radiation, and temperature on the activities of protective enzymes against active oxygen. Coral Reefs. 8, 225-232.

Lesser, M., Kruse, V., Barry, T. (2003). Exposure to ultraviolet radiation causes apoptosis in developing sea urchin embryos. J. Exp. Biol. 206, 4097-4103.

Lesser, M., Barry, T., Lamare, M., Barker, M. (2006). Biological weighting functions for DNA damage in sea urchin embryos exposed to ultraviolet radiation. J. Exp. Mar. Bio. Ecol. 328, 10-21.

Levine, M., and Davidson, R. H. (2005). Gene regulatory networks for development. P. Natl. Acad. Sci. USA. 102, 4936-4942. 
Lin, D. and Lechleiter, J. D. (2002). Mitochondrial targeted cyclophilin D protects cells from cell death by peptidyl prolyl isomerization. J. Biol. Chem. 277, 31134-31141.

Livingston, B. T., Killian, C. E., Wilt, F., Cameron, A., Landrum, M. J., Ermolaeva, O., Sapojnikov, V., Maglott, D. R., Buchanan, A. M., Ettensohn, C. A. (2006). A genome-wide analysis of biomineralizationrelated proteins in the sea urchin Strongylocentrotus purpuratus. Dev. Biol. 300, 335-348.

Madronich, S., Mckenzie, R., Bjorn, L., Caldwell, M. (1998). Changes in biologically active ultraviolet radiation reaching the Earth's surface. In: Environmental effects of ozone depletion: 1998 assessment (ed. van der Leun, J., Tang, X., Tevini, M.), pp 5-19. New York: Environment programme report, United Nations.

Marchler-Bauer, A., Anderson, J. B., Chitsaz, F., Derbyshire, M. K., DeWeeseScott, C., Fong, J. H., Geer, L. Y., Geer, R. C., Gonzales, N. R., Gwadz, M., He, S., Hurwitz, D. I., Jackson, J. D., Ke, Z., Lanczycki, C. J., Leibert, C. A., Liu, C., Lu, F., Lu, S., Marchler, G. H., Mullokandov, M., Song, J. S., Tasneem, A., Thanki, N., Yamashita, R. A., Zhang, D., Zhang, N., Bryant, S. H. (2009). CDD: specific functional annotation with the conserved domain database. Nucleic Acids Res. 37, D205-D210.

Marshak, A. (1949). Recovery from ultra-violet light-induced delay in cleavage of Arbacia eggs by irradiation with visible light. Biol. Bull. 97, 315-322.

McKenzie, R., Bijorn, L., Bais, A., Islyasd, M. (2003). Changes in biologically active ultraviolet radiation reaching the Earth's surface. Photochem. Photobiol. Sci. 2, 5-15.

McKenzie, R. L., Aucamp, P. J., Bais, A. F., Björn, L. O., Ilyas, M. (2007). Changes in biologically-active ultraviolet radiation reaching the Earth's surface. Photochem. Photobiol. Sci. 6, 218-231.

Miller, B. and Emlet, R. (1997). Influence of nearshore hydrodynamics on larval abundance and settlement of sea urchins Strongylocentrotus franciscanus and S. purpuratus in the Oregon upwelling zone. Mar. Ecol. Prog. Ser. 148, 8394.

Moreau, J. L., Marques, F., Barakat, A., Schatt, P., Lozano, J. C., Peaucellier, G., Picard, A., Genevière, A. M. (1998). Cdk2 activity is dispensable for the onset of DNA replication during the first mitotic cycles of the sea urchin early embryo. Dev. Biol. 200, 182-197. 
Murray, A. and Kirschner, M. (1989). Cyclin synthesis drives the early embryonic cell cycle. Nature. 339, 275-280.

Norbury, C. and Nurse, P. (1992). Animal cell cycles and their control. Annu. Rev. Biochem. 61, 441-470.

Oliveri, P. and Davidson, E. H. (2004). Gene regulatory network controlling embryonic specification in the sea urchin. Curr. Opin. Genet. Dev. 14, 351360.

Parker, S. H., Parker, T. A., George, K. S., Wu, S. (2006) The roles of translation initiation regulation in ultraviolet light-induced apoptosis. Mol. Cell Biochem. 293, 173-181.

Pavey, S., Russell, T., Gabrielli, B. (2001). G2 phase cell cycle arrest in human skin following UV irradiation. Oncogene. 20, 6103-6110.

Peak, M. and Peak, J. (1990). Hydroxyl radical quenching agents protect against DNA breakage caused by both $365-\mathrm{nm}$ and gamma radiation. Photochem. Photobiol. 51, 649-652.

Pennington, J. T. and Emlet, R. B. (1986). Ontogenetic and diel vertical migration of a planktonic echinoid larvae, Dendraster excentricus (Eschscholtz): occurrence, causes, and probable consequences. J. Exp. Mar. Biol. Ecol. 104, $69-95$.

Perkins, D. N., Pappin, D. J. C., Creasy, D. M., Cottrell, J. S. (1999). Probabilitybased protein identification by searching sequence databases using mass spectrometry data. Electrophoresis. 20, 3551-3567.

Pesando, D., Huitorel, P., Dolcini, V., Angelini, C., Guidetti, P., Falugi, C. (2003). Biological targets of neurotoxic pesticides analyzed by alteration of developmental events in the Mediterranean sea urchin, Paracentrotus lividus. Mar. Environ. Res. 55, 39-57.

Pourzand, C. and Tyrell, R. M. (1999). Apoptosis, the role of oxidative stress and the example of solar UV radiation. Photochem. Photobiol. 70, 380-390.

Przeslawski, R. (2004). A review of the effects of environmental stress on embryonic development within intertidal gastropod egg masses. Molluscan Res. 24, 4363.

Przeslawski, R., Davis, A. R., Benkendorff, K. (2005). Synergistic effects associated with climate change and the development of rocky shore mollusks. Global Change Biol. 11, 515-522. 
Rao, B., and Hindgardner, R. (1965). Analysis of DNA synthesis and x-ray induced mitotic delay in sea urchins. Radiat. Res. 26, 534-537.

Rhind, N. and Russell, P. (2000). Chk1 and Cds1: linchpins of the DNA damage and replication checkpoint pathways. J. Cell Sci. 113, 3889-3896.

Robinson, D. N., and Spudich, J. A. (2000). Towards a molecular understanding of cytokinesis. Trends Cell Biol. 10, 228-237.

Roux, M. M., Townley, I. K., Raish, M., Reade, A., Bradham, C.A., Humphreys, G., Gunaratne H. J., Killian, K. E., Moy, G., Su, Y., Ettensohn, C.A., Wilt, F., Vacquier, V. D., Burke, R. D., Wessel, G., Foltz, K. R. (2006). A functional genomic and proteomic perspective of sea urchin calcium signaling and egg activation. Dev. Biol. 300, 416-433.

Roux, M. M., Radeke, M., Goel, M., Mushegian, A., Foltz, K. R. (2008). 2DE identification of proteins exhibiting turnover and phosphorylation dynamics during sea urchin egg activation. Dev. Biol. 313, 630-647.

Russell J. and Phillips, N. E. (2009). Synergistic effects of ultraviolet radiation and conditions at low tide on egg masses of limpets (Benhamina obliquata and Siphonaria australis) in New Zealand. Mar. Biol. 156, 579-587.

Russo, R., Bonaventura, R., Zito, F., Schroder, H, Muller, I., Muller, W., Matranga, V. (2003). Stress to cadmium monitored by metallothionein gene induction in Paracentrotus lividus embryos. Cell Stress Chaperon. 8, 323241.

Rustad, R. (1960). Changes in the sensitivity to ultraviolet-induced mitotic delay during the cell division cycle of the sea urchin egg. Exp. Cell Res. 21, 596602.

Rustad, R. (1964). U.V.-induced mitotic delay in the sea urchin egg. Photochem. Photobiol. 3, 529-538.

Rustad, R. (1971). Radiation responses during the mitotic cycle of the sea urchin egg. In: Developmental aspects of the cell cycle (ed. Cameron, I., Padilla, G., Zimmerman, A.), pp 127-159. New York: Academic.

Saeed, A. I., Sharov, V., White, J., Li, J., Liang, W., Bhagabati, N., Braisted, J., Klapa, M., Currier, T., Thiagarajan, M., Sturn, A., Snuffin, M., Rezantsev, A., Popov, D., Ryltsov, A., Kostukovich, E., Borisovsky, I., Liu, Z., Vinsavich, A., Trush, V., Quackenbush, J. (2003). TM4: A free, 
open-source system for microarray data management and analysis.

Biotechniques. 34, 374-378.

Samanta, M. P., Tongprasit, W., Istrail, S., Cameron, R. A., Tu, Q., Davidson, E. H., Stolc, V. (2006). The transcriptome of the sea urchin embryo. Science. 314, 960-962.

Schieven, G. L., Kirihara, J. M., Gilliland, L. K., Uckun, F. M., Ledbetter, J. A. (1993). Ultraviolet radiation rapidly induces tyrosine phosphorylation and calcium signaling in lymphocytes. Mol. Biol. Cell. 4, 523-530.

Sconzo, G., Amore, G., Capra, G., Giudice, G., Cascino, D., Ghersi., G (1997). Identification and characterization of a constitutive HSP75 in sea urchin embryos. Biochem. Bioph. Res. Co. 234, 24-29.

Sconzo, G., Palla, F., Agueli, C., Spinelli, G., Giudice, G., Cascino, D., Geraci, F. (1999). Constitutive hsp70 is essential to mitosis during early cleavage of Paracentrotus lividus embryos: the blockage of constitutive hsp70 impairs mitosis. Biochem. Bioph. Res. Co. 260, 143-149.

Setlow, R. (1974). The wavelengths in sunlight effective in producing skin cancer. A theroretical analysis. Proc. Natl. Acad. Sci. USA. 71, 3363-3366.

Shapiro, B. M. (1991). The control of oxidant stress at fertilization. Science. 252, 533-536.

Shick, J. M., Romaine-Lioud, S., Ferrier-Pagès, C., Gattuso, J.-P. (1999).

Ultraviolet-B radiation stimulates shikimate pathway-dependent accumulation of mycosporine-like amino acids in the coral Stylophora pistillata despite decreases in its population of symbiotic dinoflagellates. Limnol. Oceanogr. 44, 1667-1682.

Sinha, R. P. and Häder, D. P. (2002). UV-induced DNA damage and repair: a review. Photchem. Photobiol. Sci. 1, 225-236.

Smith, R., Prezlin, B., Baker, K., Bidigare, R., Boucher, N., Coley, T., Karentz, D., MacIntyre, S., Matlick, H., Menzies, D., Ondrusek, M., Wan, Z., Water, K. (1992). Ozone depletion: ultraviolet radiation and phytoplankton biology in natural waters. Science. 255, 252-259.

Sodergren, E., Weinstock, G. M., Davidson, E. H., Cameron, R. A., Gibbs, R. A., Angerer, R. C., Angerer, L. M., Arnone, M. I., Burgess, D. R., Burke, R. D., Coffman, J. A., Dean, M., Elphick, M. R., Ettensohn, C. A., Foltz, K. R., Hamdoun, A., Hynes, R. O., Klein, W. H., Marzluff, W., McClay, D. 
R., Morris, R. L., Mushegian, A., Rast, J. P., Smith, L. C., Thorndyke, M. C., Vacquier, V. D., Wessel, G. M., Wray, G., Zhang, L., Elsik, C. G., Ermolaeva, O., Hlavina, W., Hofmann, G., Kitts, P., Landrum, M. J., Mackey, A. J., Maglott, D., Panopoulou, G., Poustka, A. J., Pruitt, K., Sapojnikov, V., Song, X., Souvorov, A., Solovyev, V., Wei, Z., Whittaker, C. A., Worley, K., Durbin, K. J., Shen, Y., Fedrigo, O., Garfield, D., Haygood, R., Primus, A., Satija, R., Severson, T., Gonzalez-Garay, M. L., Jackson, A. R., Milosavljevic, A., Tong, M., Killian, C. E., Livingston, B. T., Wilt, F. H., Adams, N., Belle, R., Carbonneau, S., Cheung, R., Cormier, P., Cosson, B., Croce, J., Fernandez-Guerra, A., Geneviere, A. M., Goel, M., Kelkar, H., Morales, J., Mulner-Lorillon, O., Robertson, A. J., Goldstone, J. V., Cole, B., Epel, D., Gold, B., Hahn, M. E., HowardAshby, M., Scally, M., Stegeman, J. J., Allgood, E. L., Cool, J., Judkins, K. M., McCafferty, S. S., Musante, A. M., Obar, R. A., Rawson, A. P., Rossetti, B. J., Gibbons, I. R., Hoffman, M. P., Leone, A., Istrail, S., Materna, S. C., Samanta, M. P., Stolc, V., Tongprasit, W., Tu, Q., Bergeron, K. F., Brandhorst, B. P., Whittle, J., Berney, K., Bottjer, D. J., Calestani, C., Peterson, K., Chow, E., Yuan, Q. A., Elhaik, E., Graur, D., Reese, J. T., Bosdet, I., Heesun, S., Marra, M. A., Schein, J., Anderson, M. K., Brockton, V., Buckley, K. M., Cohen, A. H., Fugmann, S. D., Hibino, T., Loza-Coll, M., Majeske, A. J., Messier, C., Nair, S. V., Pancer, Z., Terwilliger, D. P., Agca, C., Arboleda, E., Chen, N., Churcher, A. M., Hallbook, F., Humphrey, G. W., Idris, M. M., Kiyama, T., Liang, S., Mellott, D., Mu, X., Murray, G., Olinski, R. P., Raible, F., Rowe, M., Taylor, J. S., Tessmar-Raible, K., Wang, D., Wilson, K. H., Yaguchi, S., Gaasterland, T., Galindo, B. E., Gunaratne, H. J., Juliano, C., Kinukawa, M., Moy, G. W., Neill, A. T., Nomura, M., Raisch, M., Reade, A., Roux, M. M., Song, J. L., Su, Y. H., Townley, I. K., Voronina, E., Wong, J. L., Amore, G., Branno, M., Brown, E. R., Cavalieri, V., Duboc, V., Duloquin, L., Flytzanis, C., Gache, C., Lapraz, F., Lepage, T., Locascio, A., Martinez, P., Matassi, G., Matranga, V., Range, R., Rizzo, F., Rottinger, E., Beane, W., Bradham, C., Byrum, C., Glenn, T., Hussain, S., Manning, G., Miranda, E., Thomason, R., Walton, K., Wikramanayke, A., Wu, S. Y., Xu, R., Brown, C. T., Chen, L., Gray, R. F., Lee, P. Y., Nam, J., Oliveri, P., Smith, J., Muzny, D., Bell, S., Chacko, J., Cree, A., Curry, S., Davis, C., Dinh, H., Dugan-Rocha, S., Fowler, J., Gill, R., Hamilton, C., Hernandez, J., Hines, S., Hume, J., Jackson, L., Jolivet, A., Kovar, C., Lee, S., Lewis, L., Miner, G., Morgan, M., Nazareth, L. V., Okwuonu, G., Parker, D., Pu, L. L., Thorn, R., Wright, R. (2006). The genome of the sea urchin Strongylocentrotus purpuratus. Science. 314, 941-952. 
Stitzel, M. L. and Seydoux, G. (2007). Regulation of the oocyte-to-zygote transition. Science. 316, 407-408.

Strathmann, R.R., Staver, J.M., and Hoffman, J.R. (2002). Risk and the evolution of cell-cycle durations of embryos. Evolution. 56, 708-772.

Sun, H. Q., Yamamoto, M., Mejullano, M., Yin, H. L. (1999). Gelsolin, a multifunctional actin regulatory protein. J. Biol. Chem. 274, 33179-33182.

Takagi, M., Absalon, M. J., McLure, K. G., Kastan, M. B. (2005) Regulation of p53 translation and induction after DNA damage by ribosomal protein and nucleolin. Cell. 123, 49-63.

Tedetti, M. and Sempere, R. (2006). Percentage of ultraviolet radiation in the Marine Enviroment. A review. Photochem. Photobiol. 82, 389-397.

Tevini, M. (1993). Molecular biological effects of ultraviolet radiation. In: $U V-B$ Radiation and ozone depletion: effects on humans, animals, plants, microorganisms, and materials (ed. Tevini M.) pp 1-16. Baca Raton, FL.: Lewis Publishers.

Thoma, F. (1999). Light and dark in chromatin repair: repair of UV-induced DNA lesions by photolyase and nucleotide excision repair. Embo. J. 18, 6585-6598.

Tomanek, L. and Sanford, E. (2003). Heat-shock protein 70 (Hsp70) as a biochemical stress indicator: and experimental field test in two congeneric intertidal gastropods (genus: Tegula). Biol. Bull. 205, 276-284.

Trautinger, F., Kindas-Mugge, I., Knobler, R.M., Honigsman, H. (1996). Stress proteins in the cellular response to ultraviolet radiation. Photochem. Photobiol. 35, 141-143.

Tyrrell, L. (1991). UV-A (320-380 nm) Radiation as an oxidative stress. In: Oxidative stress: oxidants and antioxidants (ed. by H, Sies), pp 57-83. San Diego, CA.: Academic Press.

United Nations Environment Programme, Environmental Effects Assesment Panel (2005). Environmental effects of ozone depletion and its interactions with climate change: Progress report, 2004. Photochem. Photobiol. Sci. 22, 177-184.

\section{United Nations Environment Programme, Environmental Effects Assesment} Panel (2006). Environmental effects of ozone depletion and its interactions with climate change: Progress report, 2005. Photochem. Photobiol. Sci. 5, 1324. 
Vega, R. L. and Epel, D. (2004). Stress-induced apoptosis in sea urchin embryogenesis. Mar. Environ. Res. 58, 799-802.

Vega Thurber, R. and Epel, D. (2007). Apoptosis in early development of the sea urchin, Stongylocentrotus purpuratus. Dev. Biol. 303, 336-346.

Verma, R., Chen, S., Feldman, S., Schieltz, D., Yates, J., Dohmen, J., Deshaies, R. J. (2000). Proteasomal proteomics: identification of nucleotide-sensitive proteasome-interacting proteins by mass spectrometric analysis of affinitypurified proteasomes. Mol. Biol. Cell. 11, 3425-3439.

Veselská, R. and Janisch, R. (2000). The effects of UV irradiation on changes in cytoskeleton and viability of mouse fibroblasts L929 cell line. Scripta Medica. 73, 393-408.

Wei, Z., Angerer, R.C., Angerer, L.M. (2006). A database of mRNA expression patterns for the sea urchin embryo. Dev. Biol. 300, 476-484.

Whitaker, M. (2006). Calcium at fertilization and in early development. Physiol. Rev. 86, 25-88.

Williamson, C., Schulze, P., Hargreaves, B., Seva, J. (1994). The impact of shortterm exposure to UV-B radiation on zooplankton communities in north temperate lakes. J. Plankton Res. 16, 205-218.

Wong, J., Créton, R., Wessel, G. (2004). The oxidative burst at fertilization is dependent upon activation of the dual oxidase Udx1. Dev. Cell. 7, 801-814.

World Meteorological Organization (2007). Scientific Assessment of Ozone Depletion 2006-Summary. Global Ozone Research Monitoring Project-Report 50.

Xiong, F., Kopecky, J., Nedbal, L. (1999). The occurrence of UV-B absorbing mycosporine-like amino acids in freshwater and terrestrial microalgae (Chlorophyta). Aquat. Bot. 63, 37-49.

Zamansky, G. B. and Chou, I. N. (1987). Environmental wavelengths of ultraviolet light induce cytoskeletal damage. J. Invest. Dermatol. 89, 606-606.

Zeitz, L., Ferguson, R., Garfinkel, A. (1968). Radiation-induced effects on DNA synthesis in developing sea urchin eggs. Rad. Res. 34, 200-208.

Zepp. R. G., Callaghan, T. V., Erickson, D. J. (2003). Interactive effects of ozone depletion and climate change on biogeochemical cycles. Photochem. Photobiol. Sci. 2, 51-61. 
